\title{
Models for Dispatch of Volunteers in Daily Emergency Response
}
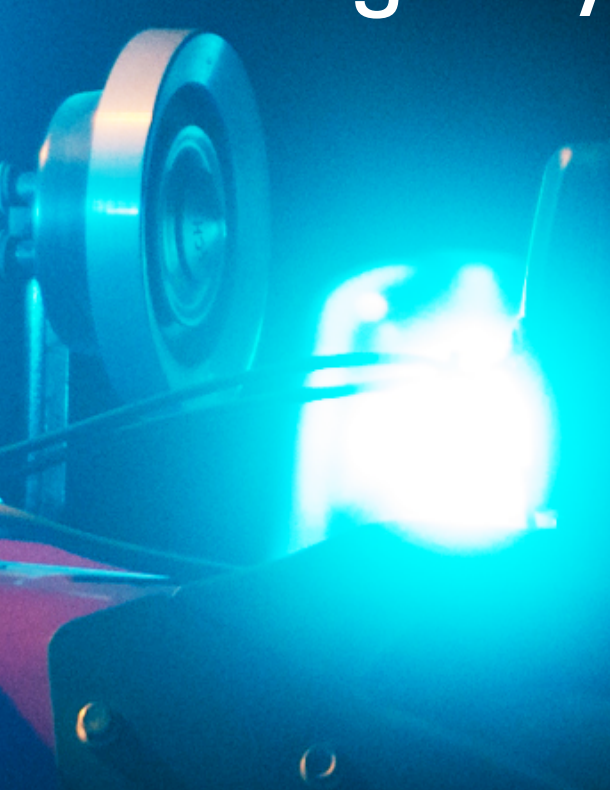

Niki Matinrad 

Linköping Studies in Science and Technology.

Dissertation No. 2203

\title{
Models for Dispatch of Volunteers in Daily Emergency Response
}

\author{
Niki Matinrad
}

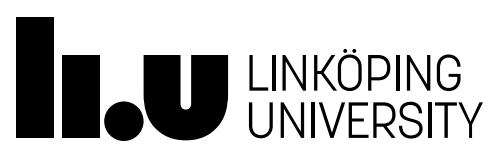

Department of Science and Technology

Linköping University, SE-601 74 Norrköping, Sweden 
(cc) EY-No This work is licensed under a Creative Commons AttributionNonCommercial 4.0 International License.

https://creativecommons.org/licenses/by-nc/4.0/

Models for Dispatch of Volunteers in Daily Emergency Response

Niki Matinrad

Linköping Studies in Science and Technology. Dissertation No. 2203

Copyright () 2022 Niki Matinrad, unless otherwise noted.

Cover photo taken by Thor Balkhed.

ISBN 978-91-7929-184-6 (print)

ISBN 978-91-7929-185-3 (PDF)

ISSN 0345-7524

Linköping University

Department of Science and Technology

SE-601 74 Norrköping, Sweden

Printed by LiU-Tryck, Linköping, Sweden, 2022 
To my parents 


\section{Abstract}

Sufficient emergency resources are essential for emergency services to provide timely help to affected people and to minimize damage to public and private assets and the environment. Emergency services, however, face resource shortages and increasing demand over time. As a result, their response times increase, resulting in lower survival chances of affected people and more severe damage to properties and the environment. Thus, emergency services need to utilize and effectively manage all their available resources. These can be divided into traditional resources, such as ambulances, and new and emerging resources, such as volunteers. Models and methods developed using operations research (OR) methodologies can facilitate the management of these resources. However, despite a rich literature on OR-based models and methods focusing on traditional resources, the literature on new and emerging resources, and specifically volunteers, is scarce.

The aim of this thesis is to develop models and methods for task assignment and dispatch of volunteers to daily medical emergencies. This also includes forecasting models for future emergencies. The developed models and methods consider volunteer programs in Sweden and the Netherlands, employing real historical data.

The aim has been addressed through three studies, one main study and two substudies, the results of which are presented in the six included papers. The main study focuses on the development of models, methods, and strategies for task assignment and dispatch of volunteers to out-of-hospital cardiac arrest (OHCA) cases using OR. To evaluate the survival rates of these patients, the most important health outcome of a response process, survival functions have been used in the development of these models and strategies. The results of this study are presented in Papers II-V. The first sub-study investigates different types of new and emerging resources used in daily medical emergency response, and the results are presented as an overview of the literature in Paper I. The second sub-study focuses on the forecast of medical emergency demand, and its outcomes are presented in Paper VI.

The overall conclusion is that the use of OR-based models and methods can contribute to improved outcomes and increased survival probabilities compared to the strategies and techniques used in the existing systems. 


\section{Sammanfattning}

För att räddningsorganisationer som till exempel ambulanssjukvården och den kommunala räddningstjänsten snabbt ska kunna hjälpa drabbade människor, byggnader och miljö, krävs att de har tillräckligt med resurser. Dock ökar hela tiden antalet utryckningar, samtidigt som budgetnedskärningar och rekryteringsproblem påverkar resurstillgången. Detta leder till längre insatstider, vilket ger ökad dödlighet och ökade kostnader. Därför är det av högsta vikt att de befintliga räddningsresurserna används så effektivt som möjligt. Dessa kan delas in i traditionella resurser, som till exempel ambulanser, och nya resurser, som frivilliga personer. Matematiska modeller, som optimerings- och simuleringsmodeller, har länge använts för att stödja planeringen och resurshanteringen av traditionella räddningsresurser, men för frivilliga resurser är det ett mer outforskat område.

Syftet med forskningen som presenteras i denna avhandling är att utveckla modeller och metoder för tilldelning av arbetsuppgifter och utlarmning av frivilliga insatspersoner till akuta sjukdomsfall. I detta ingår också modeller för att prognosticera dylika händelser. De utvecklade modellerna och metoderna baseras på, och är framtagna för att stödja, verkliga frivilliginitiativ i Sverige och Nederländerna.

Syftet uppfylls genom tre olika studier som presenteras via sex forskningsartiklar i avhandlingen. I den första studien görs en litteraturöversikt över nya typer av räddningsresurser som används som komplement till ambulanssjukvård. Den andra studien fokuserar på utvecklingen av modeller, metoder och strategier för uppgiftstilldelning och utlarmning av frivilliga insatspersoner vid hjärtstopp. I den tredje studien presenteras en ny prognosmodell för att prediktera ambulansuppdrag.

Den generella slutsatsen är att beslutsstöd baserat på matematisk modellering kan bidra till bättre utfall, och en ökad överlevnadsgrad, jämfört med de strategier för uppgiftstilldelning, utlarmning och prognostisering som används idag. 


\section{Acknowledgments}

This PhD journey has been a roller coaster ride with many ups and downs. At times, the upward stretches were long and slow while the downward ones were deep, feeling as though they would never end. Despite all the challenges along the way, it was a very enjoyable experience, giving me the opportunity to learn many lessons and grow. It would not have been possible to finish this roller coaster ride and write this thesis alone; I have been lucky to have had many people with me throughout this time, cheering me on, helping me, and supporting me, to whom I am sincerely grateful.

First and foremost, I would like to thank my supervisors, Tobias Andersson Granberg, Jan Lundgren, and Anna Fredriksson, for the invaluable time and effort they spent sharing their knowledge with me. I am deeply grateful to Tobias for being a constant source of support and encouragement, having enduring patience and belief in me, pushing me to my limits to constantly grow, being always available for guidance, discussion, and developing ideas, and being invariably a reliable collaborator. I am sincerely grateful to Jan and Anna for always supporting me and going above and beyond by patiently giving me guidance and feedback, and providing their critical views on the work, which helped me to continuously improve. I am very happy to have had all three of you as my supervisors and it is thanks to your knowledge, experience, and patience that this thesis has turned out as it is now. It has been a pleasure working with you!

I would like to thank all my other co-authors and collaborators who contributed to this research: Vangelis Angelakis, Nicklas Ennab Vogel, Melanie ReuterOppermann, Derya Demirtas, and Tom Kooy. I would also like to thank the Center for Healthcare Operations Improvement and Research (CHOIR), especially Derya Demirtas and Erwin Hans, for hosting my study visit to the University of Twente. Even though my visit was cut short due to the start of the pandemic, I had a memorable stay, especially thanks to Eline, Nicky, Stef, Jasper, and Maarten.

Also, I would like to extend my gratitude to all my colleagues at the Division of Communication and Transport Systems (KTS) for the friendly and supportive working environment, which I profoundly missed while working from home during the pandemic. A special thank you to Viveka Nilson and Sophie Lindesvik, for helping with everything, with great positivity and spirit; you are invaluable. Thank you, Christiane, and Scott, I always enjoyed our conversations. I am particularly 
grateful to the group of $\mathrm{PhD}$ students (present and former), it has always been a pleasure to spend time with you. Special thanks to Mats, Nils, and Petter for their continuous and committed collaboration in representing KTS PhD students. My sincere thanks go to Alan and Therese, whose presence and support (even from the parental leave) was a positive source of energy. I enjoyed all our interesting talks!

This research was financed by The Swedish Civil Contingency Agency (Myndigheten för samhällsskydd och beredskap, MSB), and has been part of the Center for Advanced Research in Emergency Response (CARER), for which I am very grateful.

Additionally, I would like to thank my wonderful and supportive friends. Saghi, thank you for always being there no matter what, supporting me, helping me with everything and anything, patiently listening to me, and reassuring me that the life goes on and that there will be a light at the end of the tunnel. Mina S., thanks for all your unconditional help and support, our talks, and all the fun times and celebrations. Mina M., thanks for your support and all the nice conversations we had. Nahid, Saba, Azin, Shiva, Parisa, Ana Sofia, Elmira, Fahimeh, Ehsan, Johannes, Sara K., and Hedieh, thank you for being such amazing friends anyone could ask for. I am very lucky to know you all.

Above all, a very special and huge thanks from the bottom of my heart goes to my family. My dear parents, Homa and Ebrahim, thank you for your unconditional love, unfailing belief, never-ending support and motivation, and for always giving me guidance about everything. My brother, Arash, and my sister-in-law, Negar, thank you for making my transition to Sweden so easy, showing me everything, taking me around, introducing me to people, supporting me, and being there for me. My lovely nephew, Kian, thank you for being born into our family, brightening our lives, and ensuring that I play with cars and trucks enough to make up for all the times that I never did so in my life before you were around!

Norrköping, December 2021

Niki Matinrad 


\section{List of included papers}

I. Matinrad, N. and Reuter-Oppermann, M. (2021). A review on initiatives for the management of daily medical emergencies prior to the arrival of emergency medical services. Central European Journal of Operations Research, 1-52.

II. Matinrad, N., Granberg, T. A., Ennab Vogel, N., and Angelakis, V. (2019). Optimal Dispatch of Volunteers to Out-of-hospital Cardiac Arrest Patients. In Proceedings of the 52nd Hawaii International Conference on System Sciences (HICSS), Hawaii, USA, January 8-11, 2019, 4088-4097.

III. Matinrad, N., Granberg, T. A., and Angelakis, V. (2021). Modeling uncertain task compliance in dispatch of volunteers to out-of-hospital cardiac arrest patients. Computers \& Industrial Engineering, 159, 107515.

IV. Matinrad, N. and Granberg, T. A. Optimal pre-dispatch task assignment of volunteers in daily emergency response. Submitted for publication.

V. Matinrad, N., Demirtas, D., and Granberg, T. A. Improving volunteer response to out-of-hospital cardiac arrest using mobile automated external defibrillators. Working paper.

VI. Steins, K., Matinrad, N., and Granberg, T. A. (2019). Forecasting the Demand for Emergency Medical Services. In Proceedings of the 52nd Hawaii International Conference on System Sciences (HICSS), Hawaii, USA, January 8-11, 2019, 1855-1864. 


\section{Table of contents}

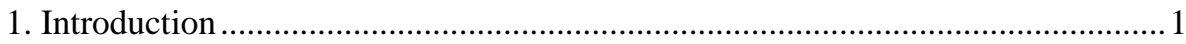

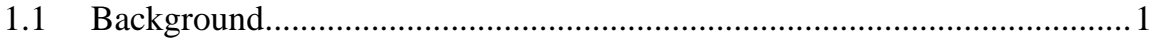

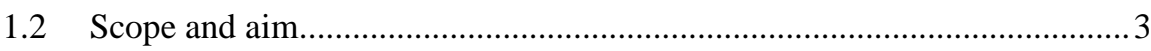

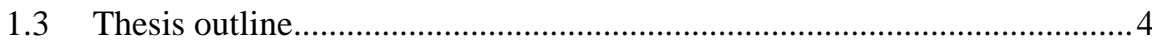

2. Emergency volunteer management ..................................................................

$2.1 \quad$ Emergency management ………………………................................

2.1.1 General concepts..............................................................................

2.1.2 Emergency management life cycle ……………………………….....

2.2 Emergency preparedness and response ..................................................... 10

2.2.1 Demand forecasting ......................................................................... 11

2.2.2 Performance of emergency response ................................................. 12

2.2.3 Dispatch and deployment of emergency medical services................. 13

2.3 Novel emergency resources.................................................................... 14

2.4 Novel human resources in emergency response ....................................... 16

2.5 Effective utilization of volunteers …………………............................. 18

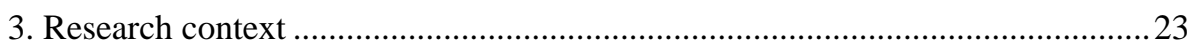

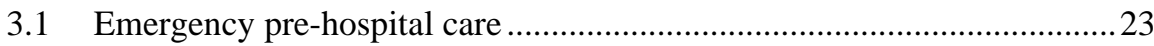

3.1.1 Emergency medical services in Sweden............................................23

3.1.2 Emergency medical services in the Netherlands .................................25

3.2 Initiatives utilizing novel human resources..............................................26

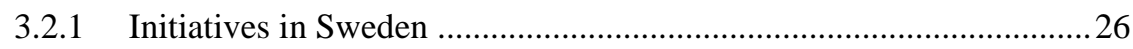

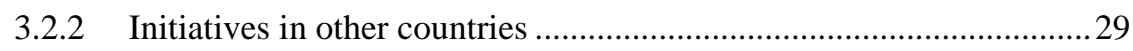

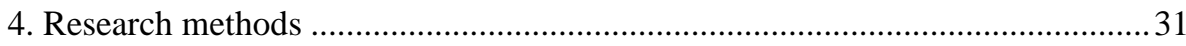

4.1 Operations research ............................................................................ 31

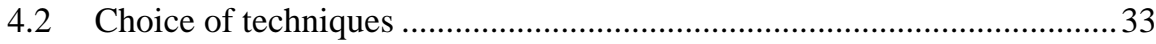

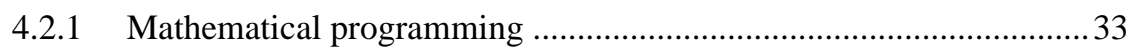

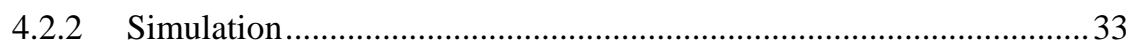




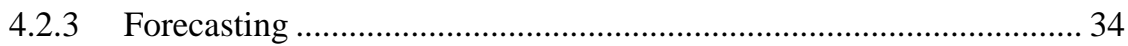

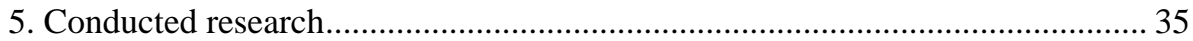

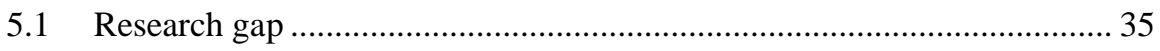

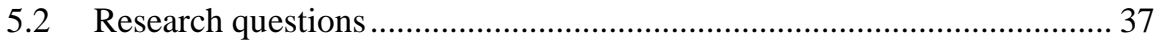

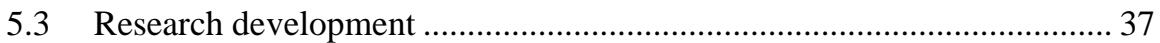

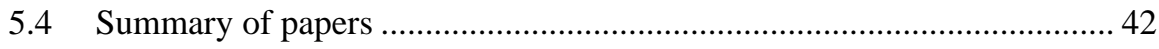

5.4.1 Paper I: A review on initiatives for the management of daily medical emergencies prior to the arrival of emergency medical services .................. 42

5.4.2 Paper II: Optimal dispatch of volunteers to out-of-hospital cardiac arrest patients

5.4.3 Paper III: Modeling uncertain task compliance in dispatch of volunteers to out-of-hospital cardiac arrest patients

5.4.4 Paper IV: Optimal pre-dispatch task assignment of volunteers in daily emergency response

5.4.5 Paper V: Improving volunteer response to out-of-hospital cardiac arrest using mobile automated external defibrillators

5.4.6 Paper VI: Forecasting the demand for emergency medical services . 49

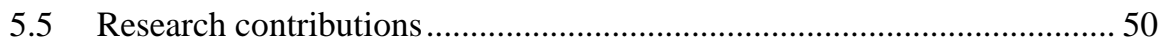

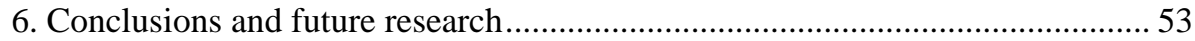

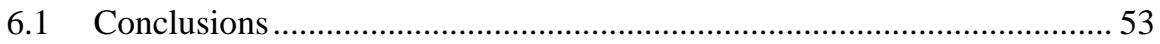

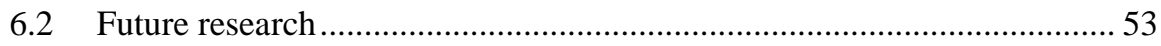

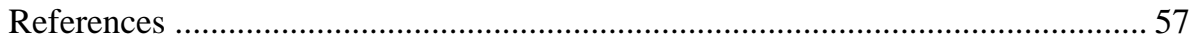

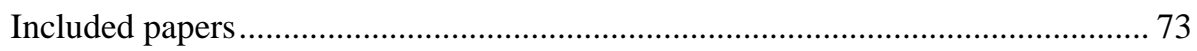




\section{Abbreviations}

AED Automated external defibrillator

ALS Advanced life support

App (Mobile phone) application

CFR Community first responders

CIP Civil insatsperson [Civilian response persons]

CPR Cardiopulmonary resuscitation

EMS Emergency medical services

EMT Emergency medical technicians

FRS Fire and rescue services

IVPA I väntan på ambulans [While waiting for the ambulance]

MAE Mean absolute error

ME Mean error

MIP Mixed integer programming

MINP Mixed integer nonlinear programming

MSB Myndigheten för samhällsskydd och beredskap [Swedish Civil Contingencies Agency]

MMT Mobile medical team

MPS Mobile positioning system

OHCA Out-of-hospital cardiac arrest

OR Operations research

RMSE Root mean squared error

SMS Short message service

ZIP Zero-Inflated Poisson 


\section{Introduction}

This chapter presents the background and motivation for this research as well as its scope and aim; it also outlines the contents of the thesis.

\subsection{Background}

Daily emergencies are events with high frequency of occurrence that have relatively low magnitude of consequences (Quarantelli, 1995). Despite this low level of consequences, given the high frequency of these emergencies, they affect many people and properties, as well as the environment worldwide. Daily emergencies are generally uncomplicated and available local resources, with their standard routines, are sufficient for their management (Quarantelli, 2000). Building fires, traffic accidents, falls, drownings, trauma, and cardiac arrests are examples of such emergencies. Any of these incidents, or the risk of occurrence of such an incident, results in a demand for assistance, which requires a timely response to reduce mortality and damage. Emergency services, which include emergency medical services (EMS), fire and rescue services (FRS), and the police, are responsible for responding to such demand and managing daily emergencies. These organizations provide help to affected people and minimize damage to both public and private assets and the environment during emergencies.

Each of the emergency services has different roles and responsibilities in the management of emergencies. EMS play a vital role in the healthcare system by providing pre-hospital care and saving lives of people outside of hospitals, which can lead to a reduction in the mortality rate (Aringhieri et al., 2017; Bélanger et al., 2019; Carvalho et al., 2020; Ingolfsson, 2013; Pozner et al., 2004). FRS are primarily concerned with the safety of people, properties, and the environment, and therefore, they are responsible for activities such as rescuing people and extinguishing fires (Berlin and Carlström, 2011). The police ensure the security of the public and provide adequate protection, information, and other assistance (SFS 1984:387). Depending on the circumstances of an emergency, and in order to manage the situation, a response by one of the EMS, FRS, or police, or a collaborative response by some or all of them, might be needed. 
Emergency services use different resources, including physical equipment, vehicles, personnel, and information. Regardless of the type of emergency, the availability of these resources affects the level of service that emergency services can provide. Emergency services are, however, challenged by: (1) cost pressures and budget cutbacks (Yousefi Mojir and Pilemalm, 2016) resulting from the budget constraints that local authorities face (Weinholt, 2015), and (2) the issue of long distances to sparsely populated areas (Yousefi Mojir and Pilemalm, 2016). The cost pressures negatively affect existing limited resources and enforce more limitations on them. The long distances to sparsely populated areas mean longer response times to those regions. Extreme situations, such as the COVID-19 pandemic, can intensify the issue of emergency resource shortages by placing high demand on limited emergency resources. Such large-scale circumstances require an extensive utilization of the resources of emergency organizations (Yu et al., 2019), and this affects the availability of resources for the management of daily emergencies. An increase in the number of emergencies or a change in the distribution of populations across regions can also affect the service level provided by the emergency services.

The combination of higher rates of demand and limited available resources will lead to longer response times. Thus, it will be difficult or even impossible to achieve the ideal response time, given the available resources, for everyone in need of assistance by the emergency services, at any point in time, and across all service regions. Longer response times reduce the survival chances of affected people and increase the amount of loss and damage to properties and the environment. The later the emergency services arrive at an incident site, the more severe the damage to people and properties can become. This is evident in cases such as trauma and cardiac arrest (Waalewijn et al., 2001) and fires (Jaldell, 2004). Additional resources can be used in daily emergency response systems to mitigate the effects of a lack of sufficient emergency resources.

The available resources that can be utilized in emergency responses can be roughly divided into traditional and new and emerging ones. A systematic employment of all available resources is needed to: (1) reduce the overall impact and consequences of daily emergencies over time, (2) ensure that everybody receives an equal level of service and protection against accidents, and (3) ensure that rescue efforts have a reasonable response time.

Traditional emergency resources, such as ambulances and paramedics, are already an integral part of existing emergency response systems. These resources are well-established within emergency response systems and are systematically used in daily emergency responses. 
New and emerging emergency resources (henceforth called novel emergency resources), such as volunteers, are considered new, not because of their identities or features, but because they have not previously been part of the existing emergency response systems in an organized or semi-organized manner. The establishment and systematic use of novel emergency resources requires: (1) an understanding of their potential contribution to emergency response systems, (2) proper integrations of these resources into the response systems, and (3) the availability of models and methods to enable their effective use in daily emergency responses.

The literature on novel emergency resources shows that several researchers have investigated use-cases of these resources, as well as the potential benefits of their utilization. The lack of sufficient traditional emergency resources, as well as positive results from these studies, have led to the worldwide introduction and implementation of initiatives in which novel emergency resources are used for daily emergency response. Examples of such initiatives include operational volunteer programs for out-of-hospital cardiac arrest (OHCA) cases (Andelius et al., 2021; Oving et al., 2019; Scquizzato et al., 2020), for helping in cases of different daily emergencies in rural areas (Ramsell et al., 2017), and for helping to find missing people (Missing People Sweden, n.d.).

These programs usually use simple static rules to make decisions about volunteer dispatch and task assignments. The static nature of these rules makes it difficult to incorporate any other measures, such as survival probability of patients, in order to evaluate the outcome of each decision. As the purpose of these programs and initiatives is to help reduce damage and save more lives, advanced and dynamic strategies, models, and methods can potentially contribute to achieving such goals better than their static counterparts. However, a lack of such models and methods, both in the practice and the existing literature, is prominent. For instance, despite the good number of operational volunteer programs around the world, published advanced and dynamic models and methods for the systematic use of volunteers, such as their dispatch and task assignment in daily emergencies, are nonexistent.

\subsection{Scope and aim}

The scope of this thesis is daily medical emergencies, and the focus is on volunteers, which is part of novel emergency resources (see Figure 1). Volunteers can be used in different daily emergency responses; in this research, the primary focus is on the utilization of volunteers for OHCA cases.

The aim is to develop models, methods, and strategies for task assignment and dispatch of volunteers to daily emergencies. These models, methods, and strategies 
are developed using operations research (OR) and tested on the data from volunteer programs in Sweden and the Netherlands as use-cases. Validating the developed models and methods using real data from these use-cases makes it possible to ensure that these models have the potential to be used for real practical problems as well.

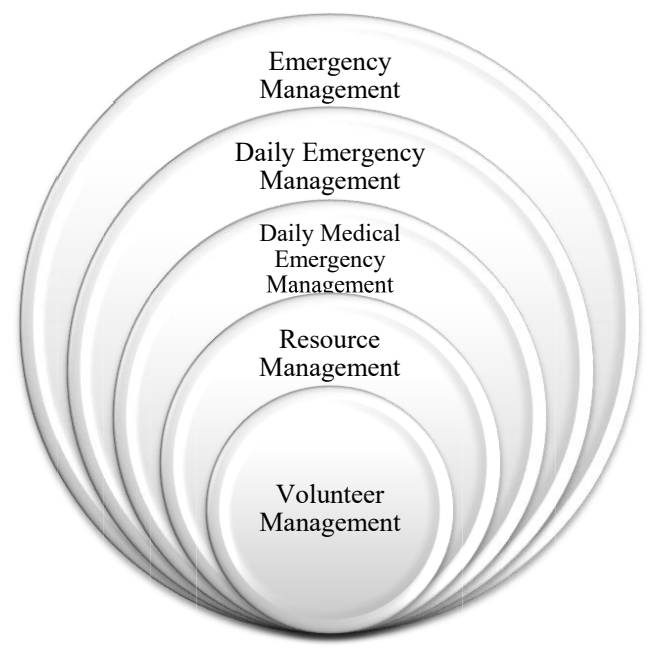

Figure 1. Scope of this thesis

\subsection{Thesis outline}

The remainder of this thesis is organized as follows. Chapter 2 presents the background to volunteer management within the area of emergency management. In Chapter 3, the research context is described. Research methods are presented in Chapter 4, including the motivation for the choice of methods and a brief description of the methods used in this thesis. Chapter 5 describes conducted research, specifying the research questions and research contributions. This chapter also contains a summary of the papers that are included in the thesis. Finally, in Chapter 6 , conclusions and an outline for future research are presented. 


\section{Emergency volunteer management}

This chapter first describes general concepts relating to emergencies and their management, the emergency management life cycle, and a few example studies that have addressed EMS problems using OR. The chapter continues by providing a background on volunteer management in daily emergencies, and thereby, it presents novel emergency resources for daily medical emergency responses and a summary of a few works that focus on the management of volunteers for daily medical emergencies.

\subsection{Emergency management}

The focus of this thesis, as shown in Figure 1, is volunteer management as part of the resources used for daily emergency management, which itself is a part of emergency management. Thus, in this section, general concepts relating to emergency management are presented, along with the emergency management life cycle.

\subsubsection{General concepts}

Emergencies have two main aspects defining their nature: (1) frequency of occurrence, and (2) level of consequences. Different emergencies can be positioned within a two-dimensional spectrum consisting of these two aspects (see Figure 2). Daily emergencies are at one corner of the spectrum, with low consequence level but high frequency, and disasters are at the opposite corner, where the frequency of occurrence is low but the consequence level is high. Emergencies, regardless of their position within this spectrum, affect humans, properties, and the environment. Although daily emergencies are events with a low level of consequences, considering their high frequency of occurrence, over time, the number of people affected and the amount of environmental damage caused by these events are comparable to those of disasters (Yousefi Mojir, 2016). It should be noted that some areas of this emergency spectrum might contain only a small number of emergencies or be free of any emergency, for example, where both consequence level and frequency are high. Regardless of the nature of an incident or its position within the emergency spectrum (e.g., daily emergency or disaster), emergency organizations are mainly responsible for managing them. 


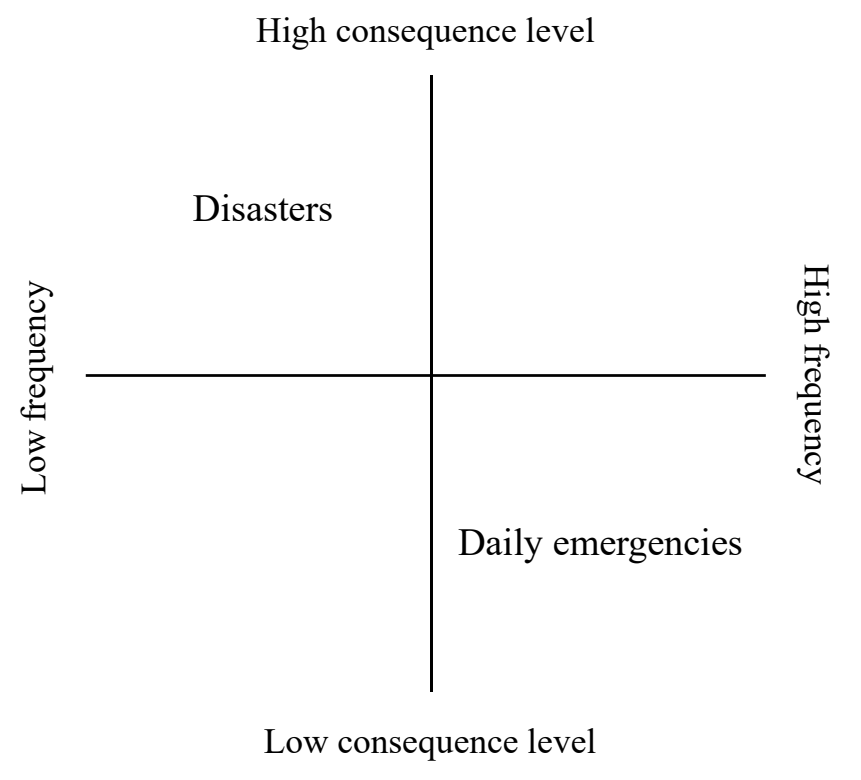

Figure 2. Emergency spectrum

Emergencies across the emergency spectrum can have natural origins, or they can be man-made. In emergencies with natural origins, humans play an insignificant or no effective role in their occurrence. Strokes, cardiac arrests, forest fires, and floods are examples of such emergencies. The actions of humans can, however, lead to the occurrence of some other emergencies, such as drownings, traffic accidents, shootings, airplane crashes, and terrorist attacks, which all form man-made emergencies.

As stated by Taber (2008), under unfortunate circumstances, daily emergencies can evolve into bigger and more complicated events. This means that a daily emergency, such as a small fire, combined with inclement weather and other unforeseen factors, can escalate into a bigger emergency involving more people, property, and the environment. However, for this to occur, the emergency itself must have the capacity to evolve into a bigger incident, which means that some emergencies, such as stroke, are inapplicable of such evolvements.

Emergencies can be categorized solely based on the two main aspects of the emergency spectrum; however, across different societies, some other parameters may also affect their categorization. Parameters such as the geographical location of a society, its culture, and the quality of its infrastructures affect the definition of 
emergencies (Bull-Kamanga et al., 2003). Consequently, a major emergency in one society might be considered a minor one in another society, and vice versa. In Sweden, daily emergencies include building fires, traffic accidents, falls, drownings, non-building fires, building collapses, a person in danger, an animal in danger, the emission of dangerous substances, and water damage (MSB, n.d.). This classification can be applicable to other countries with a similar societal and infrastructural development level.

Emergency management requires recognition of the potential risks that a society might face. After such recognition, it is possible to take relevant preventive and reactive measures to remove or reduce the consequences of those risks. Simply defined, emergency management is "the discipline of dealing with risk and risk avoidance" (Haddow et al., 2013). Different circumstances can entail different outcomes as well as different management requirements. Therefore, considering the circumstances of an emergency rather than the event itself is necessary for an efficient emergency management (Erickson, 2006). Many emergencies require a rapid response and the later emergency services arrive at the site of the emergency, the more severe the situation can become, such as in cases of trauma or cardiac arrest (Waalewijn et al., 2001). A quick response and timely actions by emergency services at the scene of the event can prevent the situation from worsening or escalating into a more complicated situation, which could potentially require more emergency resources or complex interventions.

It is important to differentiate between the management of emergencies depending on where they place on the emergency spectrum. All emergency organizations have standard routines to manage daily emergencies that are not easily interrupted and are part of their everyday activities (Quarantelli, 1995, 2000). In addition to these, emergency organizations do not lose their relative independence when handling daily emergencies, and their behavioral norms do not change. In response to a disaster, however, emergency organizations might need to follow different routines and protocols from the ones they use in everyday settings for daily emergency responses. During disasters, behavioral norms will change, and local resources cannot cover the rising demand, requiring a fast formation of collaboration and trust with other resource providers (Tatham and Kovács, 2010).

\subsubsection{Emergency management life cycle}

Emergency management life cycle consists of four phases: mitigation, preparedness, response, and recovery (see Figure 3). Although this life cycle is seen mostly in disaster management literature (see for example works of Coppola (2006), Haghani and Afshar (2009), Haddow et al. (2013), and Nikbakhsh and Farahani 
(2011)), it is applicable to emergencies of other types and scales, including daily emergencies.

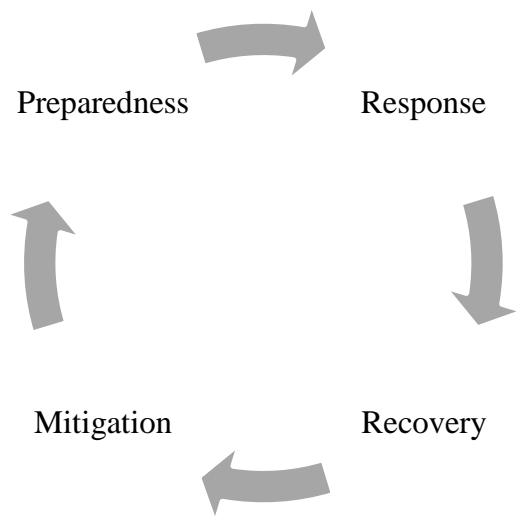

Figure 3. Emergency management life cycle

Depending on the nature of an emergency, and in relation to the time when it occurs and develops, these four phases can be categorized into three (e.g., Gupta et al. (2016)) or two classes. The two-class categorization breaks down the life cycle into "before" and "after" categories, with mitigation and preparedness constituting "before" and response and recovery "after". This categorization is suitable for emergencies that happen fast, and thus, it is (almost) impossible to respond while the incident is occurring, for example, a traffic accident. The three-class categorization includes a "during" category as well as "before" and "after" categories. In this categorization, mitigation and preparedness form "before", response belongs to "during", and recovery forms "after". When the emergency has a slow onset, such as a building fire, response can take place while the emergency is ongoing, and thus, a three-class categorization can be used. In both categorization methods, phases in the "before" category include activities that are undertaken prior to the occurrence of an emergency, whereas activities in the "after" category begin after an incident has occurred. A short description of each of the four phases follows:

- Mitigation: this phase aims to apply measures that can prevent the occurrence of an emergency or reduce its effects (Nikbakhsh and Farahani, 2011). For example, the installation of smoke detectors in buildings helps in the early identification of fires, which can contribute to the prevention of an emergency.

- Preparedness: in this phase, emergency organizations prepare their response plans and perform activities prior to the occurrence of an emergency in order to strengthen their preparedness capabilities and to be 
ready to adequately manage the emergency (Haddow et al., 2013; Rottkemper et al., 2011). Periodic practice drills performed by emergency organizations to maintain the required preparedness level among personnel is an example of preparedness activities.

- Response: this phase includes immediate actions after the occurrence of an emergency, with the aim of saving lives and properties and preserving the environment (Berkoune et al., 2012). Example activities include to dispatch resources, including manpower, necessary items for people in need, and equipment for the dispatched manpower (Nikbakhsh and Farahani, 2011), to rescue and take care of injured individuals, to extinguish fires, to secure and police the area, and to restore order (Haddow et al., 2013).

- Recovery: this phase includes handling the secondary needs of the people affected by the emergency after their primary needs have been met during the response phase (Nikbakhsh and Farahani, 2011). However, it is difficult to clearly determine when this phase begins (Haddow et al., 2013). Taking care of the needs of patients in hospitals or rehabilitation centers and rebuilding and restoring structures damaged by fire are examples of activities in this phase.

In this thesis, the focus is on the preparedness and response phases of the emergency management life cycle. Emergency preparedness and response activities require different types of resources, including information, personnel, vehicles, and physical items. As the main organizations involved in the emergency preparedness and response, EMS, FRS, the police, and call centers are common providers of these resources. Regardless of emergency type, the availability of the required resources affects the level of service that emergency organizations can provide. Depending on the type of emergency, one or several of the emergency organizations are needed to respond to it. EMS, FRS, and the police each have their individual responsibilities and roles. However, when at the scene of an emergency, they might perform some tasks that are outside of their usual responsibilities to cover for a lack of resources from other organizations, or they might form collaborations with each other according to their predefined routines and protocols.

According to Bélanger et al. (2019), problems related to EMS, such as their location, relocation, and dispatch, can be categorized into strategic, tactical, and operational levels. Such a categorization is nonetheless applicable to the other emergency organizations as well. In relation to the emergency management life cycle, strategic- and tactical-level problems are related to the preparedness phase, and operational ones to the response phase. The aim of decisions at all levels is that 
everyone, as far as possible, receives an equal level of service and protection in a timely manner, using the existing limited resources.

To perform a response in a timely manner, an adequate plan for the employment of emergency resources should already exist. Thus, activities such as logistical planning should be undertaken by all emergency organizations, including EMS, prior to the occurrence of an emergency and during the preparedness phase. Decisions about problems related to the location of stations, the allocation of resources to the stations, the location and relocation of the emergency fleet, the location of standby sites, and the scheduling of resources need to be made at the strategic and tactical levels. To improve decision-making for these problems during the preparedness phase, information about future medical emergency demand can be beneficial. Forecasting models can be used to predict this demand and to provide the necessary information.

At the operational level, emergency organizations make short-term decisions (i.e., operational decisions) to provide the best possible service in response to an emergency. During the response phase, these organizations activate their emergency plans, which they have laid out during the preparedness phase, to utilize their available resources in the best possible way. Dispatch (deployment) of emergency resources, and cooperation between the resources of different organizations, are among the decisions made during the response phase.

Different criteria can be used to determine how well an emergency system performs. Examples are response time, the survival rate of victims, and the amount of loss and damage. Response time is considered an important factor since it has a direct impact on human lives, properties, and the environment (Swersey, 1994). Other criteria, including survival rate and the amount of loss and damage, are affected by response time as well.

\subsection{Emergency preparedness and response}

In this section, the focus will be on the preparedness for and response to daily medical emergencies, and a brief description of some of the works, where OR has been applied, will be given. The presented works are related to the forecasting of daily medical emergency calls, the performance of emergency response focusing on EMS planning problems, and problems related to the EMS response phase. These works and their presented models and methods can be used as steppingstones for further studies on EMS problems as well as for the development of models and methods for novel emergency resources (e.g., dispatch of volunteers) using OR. 


\subsubsection{Demand forecasting}

Performing activities such as logistical planning during the preparedness phase can be challenging. The main reason for this difficulty, as mentioned by Ingolfsson (2013) regarding EMS, is the high variability in location and severity of an emergency as well as the volume of calls requiring an emergency response. To overcome this difficulty, emergency organizations need information about the time, location, and type of potential future emergencies. Such information can be provided using forecasting models that rely on historical events. Researchers have used demand, response times, and workload from the records of previous emergencies as the main input elements for their forecasting models.

When the focus of forecasting is to predict future events in relation to time, time series can be a suitable method for modeling. The aim of forecasting in these models can be to determine the expected number of future emergency calls at a fine time level (e.g., hour, season), and thus, only the time is included as the predictor (e.g., Matteson et al. (2011)). The models can also show other time-dependent factors affecting this number to explain any patterns in the number of calls; for example, times when people work, commute, celebrate, and sleep affecting the number of emergency calls (Channouf et al., 2007).

If the aim is to consider the effects of time-independent factors, such as socioeconomic and demographic characteristics, on the number of calls, and to include these factors in the model, time series will not be the best choice. Instead, regression models can be used to make a forecast while considering such timeindependent explanatory variables. Independent variables such as age (Aldrich et al., 1971; Lowthian et al., 2011; Svenson, 2000; Wong et al., 2019; Wong and Lai, 2012), location, poverty (per capita income, percentage of households with no wage earner, percentage of residents below the poverty level) (Svenson, 2000), weather variables, triage level (Wong and Lai, 2012), the accessibility of hospitals without an emergency room, and the accessibility of emergency ambulance services (Wong et al., 2019) can all be incorporated into these models to forecast the number of emergency calls and to draw conclusions about how each of these variables affects the number of emergency calls. The results of such regression models can show, for instance, that elderly people contribute to a higher rate of ambulance calls or that in rural areas the percentage of residents with a middle-school education and higher is among affecting factors.

Alternatively, if the goal is to predict future values based on time and timedependent factors as well as time-independent factors, models that consider time and location simultaneously, or "spatial-temporal" models are employed. Using these models makes it possible to forecast the amount of emergency demand for 
different times of the day in specific geographical locations (Nicoletta et al., 2016; Setzler et al., 2009). Such models can determine both spatial and temporal factors within the same framework. For instance, it has been shown that residential areas have more demand during morning hours, commercial areas create more ambulance demand during afternoon hours, and areas with higher population density, a larger proportion of individuals older than 40 years, and more heterogenous land use create more ambulance demand (Habib et al., 2018).

\subsubsection{Performance of emergency response}

The work of EMS and their performance has a direct effect on the health outcomes of patients (e.g., survival). Therefore, it is reasonable to develop models that can directly take into account criteria such as the survival chances of patients, and the fairness and equity levels of delivered services.

In emergency cases, especially medical ones, the survival of patients can be considered the most important health outcome of an emergency response. A survival function can thus be incorporated into OR models, such as optimization models, to evaluate the outcome of the planning and operational problems in relation to survival. A single survival function can be included as an objective function in a coverage model for the location of EMS stations, resulting in a survival-maximizing location model (Erkut et al., 2008), or different survival functions for different classes of patients can be used in a maximal expected survival location model for the same problem (Knight et al., 2012). Alternatively, such functions can be used for the problem of EMS base station locations and the allocation of ambulances, incorporating the functions into a genetic algorithm with an integrated EMS simulation model (McCormack and Coates, 2015). A model for obtaining optimal dispatching strategies can aim to maximize patient survival (Bandara et al., 2012), or a simulation can be used to investigate different dispatching policiesconsidering the priority of the call-in order to evaluate EMS systems in terms of the survival chances of patients (Bandara et al., 2014).

The population across EMS service regions can be spread widely, which can mean that some people will have longer travel times or worse access to emergency help. Therefore, the need for a fair emergency system to provide help with a good equity level becomes more prominent. With such goals, a fair emergency system under uncertainty can be designed to minimize the disutility perceived by the worst situated user (Kvet and Janáček, 2018), the location of ambulances can be determined using optimization models aiming to fulfill fairness of service delivery to more rural areas (areas less densely populated than urban areas) (Chanta et al., 2014), or EMS providers may use different configurations at different times rather 
than using one single system configuration when modeling the problem of ambulance location, maximizing Bernoulli-Nash social welfare (Jagtenberg and Mason, 2020). It is also possible to develop a model for optimal ambulance dispatch in which equity for both patients and ambulances is considered (McLay and Mayorga, 2013a), to include fairness and equity of delivered services in joint location and distribution decisions while considering different levels of emergency medical call priorities (Enayati et al., 2019), or to plan large-scale EMS systems with a joint decision on location and dispatch while balancing efficiency and fairness of the system (Toro-Díaz et al., 2015).

Emergency demand forecasting models can also be used to enhance the models for making decisions about EMS planning problems. The results of these models predicting future resource requirements can be used, for example, as an input to optimization models for units and personnel scheduling, determination of the location of waiting sites for ambulances, dispatching rules and relocation (Trudeau et al., 1989), as well as ambulance allocation (Tsai et al., 2018).

\subsubsection{Dispatch and deployment of emergency medical services}

Once it has been determined that a call made to an emergency call center requires the attendance and help of EMS, the call center needs to assign one or several ambulances to the emergency case. The required number of ambulances is sent directly from the ambulance stations closest to the location of the emergency, or some ambulances on their way to lower priority cases are diverted to higher priority cases. Nevertheless, the dispatch decisions should be made in such a way that a service area is not left uncovered. Therefore, determining which ambulances to send to each emergency case and where to (re)locate them can be complex. Models developed using OR have been shown to have the capability of providing solutions to such complex problems.

A model can be developed to find the optimal dispatch of ambulances, while considering error in the prioritization of patients to maximize the expected coverage for true high-risk patients (McLay and Mayorga, 2013b). It can aim to improve the availability probability of ambulances for high priority calls while considering server reservation policies (Iannoni et al., 2015), or to include demand uncertainty to obtain a robust solution (Lam et al., 2016). It is possible to use different methods to model the dispatch of ambulances, such as constraint programming, dynamic programming, and binary linear programming, while the used methods can result in the same optimal dispatch strategy (Jagtenberg et al., 2017). While determining the dispatch decisions for ambulances, it might be of similar importance to ensure proper backup coverage. Such considerations can also be included in the developed 
models to obtain both dispatch decisions and an optimal configuration for the system (Iannoni et al., 2008).

While developed models may focus solely on the dispatch problem, they might consider dispatch and (re)location problems simultaneously trying to find the best possible solutions. In the modeling of these joint problems, a preparedness measure might be included to ensure that current and future emergency calls, in any part of an area, can be responded to (e.g., Andersson and Värbrand (2007) and Carvalho et al. (2020)). The developed models might take uncertain elements into account, such as demand uncertainty or the probability that an ambulance will be unavailable (i.e., busy fraction) to provide the optimal solutions in real-time using methods such as dynamic, stochastic, or robust programming (Bertsimas and $\mathrm{Ng}$, 2019; Boujemaa et al., 2020; Schmid, 2012). To make ambulance dispatch and location decisions, an ordered list of ambulances based on their locations can be created and used within a simulation-optimization framework (Bélanger et al., 2020). Such ordered lists (also known as dispatch lists), while capable of incorporating the busy fraction, provide the hierarchy or order of ambulances and guiding dispatching decisions (Toro-Díaz et al., 2013).

\subsection{Novel emergency resources}

To find a potential solution for the lack of sufficient resources for the management of emergencies, to create safer communities, and to provide equity to people across a country, initiatives in which novel resources are utilized have started in several countries. The use of new resources, or the introduction of new roles for existing ones, in current emergency response systems can bring benefits such as reduced response times, which in turn can reduce the consequences of daily emergencies. Novel resources can be categorized into two classes of human resources and equipment.

Figure 4 illustrates the categories of resources that can contribute to emergency management. In the center of this figure is the emergency management life cycle. This life cycle is then surrounded by human resources that can play an effective role in its management: traditional human resources (top, orange ovals) and novel human resources (bottom, green ovals). While traditional resources are involved in all phases of the emergency management life cycle, novel human resources are mostly used in the response phase. Medical and transport equipment are depicted on the left and right of the emergency management life cycle, respectively. These sets of equipment contribute to both the preparedness and the response phases; the medical equipment shown in Figure 4 includes only those items that are used by novel human 
resources in medical emergencies. The arrows crossing the emergency management boundary show the connection between each group of resources and phase(s) of the life cycle.

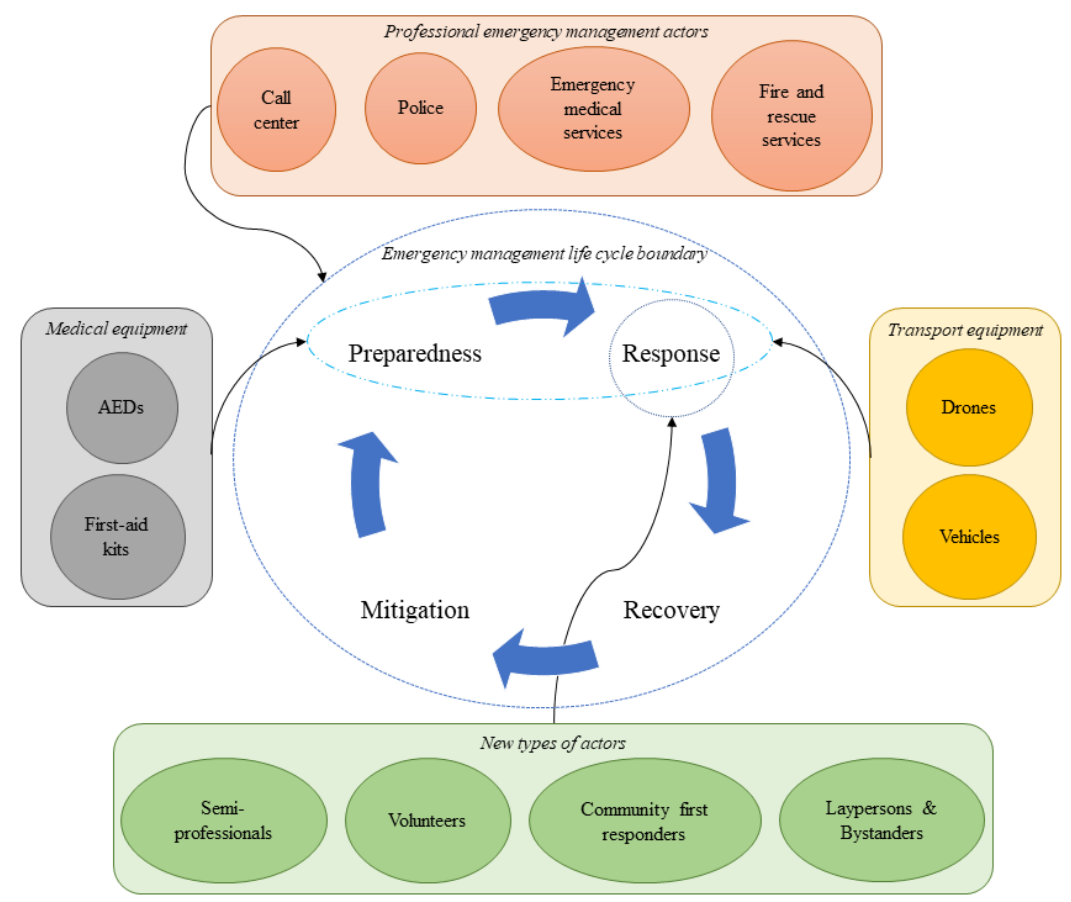

Figure 4. Actors and equipment involved in the emergency management life cycle (Reproduced from Paper I)

Equipment that is also a new part of daily emergency management includes drones, also known as unmanned aerial vehicles (UAVs). Drones, which originated as military equipment, are now used in response to different types of emergencies, ranging from disasters (e.g., Chowdhury et al. (2017), Oruc and Kara (2018), and Kim et al. (2019)) to daily emergencies (e.g., Claesson et al. (2016), Claesson, Svensson, et al. (2017), Balasingam (2017), Bäckman et al. (2018), and Schierbeck et al. (2021)). Although drones have been available for several years now, their utilization in the management of daily medical emergencies is relatively new. Drones are (being tested to be) used to deliver essential equipment such as AEDs (Pulver and Wei, 2018; Sanfridsson et al., 2019; Song et al., 2018), to help people stay afloat to prevent them from drowning (Seguin et al., 2018), or to photograph or scan an area to provide additional information about a situation (Claesson et al., 2017). Automated external defibrillators (AEDs) are another piece of equipment commonly used in response to OHCA cases. AEDs can be used to provide 
defibrillation for OHCA patients, and in many countries they are placed in public areas so that in the event of an OHCA people in the vicinity of the case can access these devices (e.g., Chan et al. (2013, 2018) and Deakin et al. (2014)). Unlike AEDs, which are used operationally in many countries, the utilization of drones for daily medical emergency response is mostly still in a pre-mature phase, including pilot studies and experimental deployments. Novel human resources might use one or several types of equipment in their emergency responses.

\subsection{Novel human resources in emergency response}

Based on the literature on the novel human resources that are used in response to daily medical emergencies, these resources can be categorized into four main groups: (1) community first responders (CFR), (2) first responders, (3) laypersons and bystanders, and (4) volunteers.

CFR are not professionally part of the medical emergency response system. However, they know how to manage some or all medical emergencies, because they have either a medical education (e.g., doctors and nurses) or basic medical training (e.g., school nurses and homecare personnel). Some CFR may also be known as semi-professionals in some initiatives and literature (e.g., Yousefi Mojir and Pilemalm (2013) and Granberg et al. (2016, 2017)).

First responders include FRS and the police as parts of the professional emergency management system; however, their primary role in this system is nonmedical (shown within professional emergency management actors in Figure 4). Thus, FRS and the police are considered to be novel human resources in relation to daily medical emergencies.

Laypersons are defined as people who "do not belong to a specific profession or are not expert in some fields" (Merriam-Webster, n.d.). Thus, in the context of daily medical emergencies, laypersons are neither affiliated with EMS nor have any formal medical training (e.g., not a doctor or nurse). Bystanders, however, may be people with a formal medical education who are passing by an emergency, such as off-duty medical workers, or they might be laypersons (Nord, 2017).

Volunteers include people who are willing to provide help without compensation, and thus, volunteer. Depending on the level of integration of volunteers within emergency response systems, their level of training, experience, responsibilities, and access to equipment varies. At one end of the spectrum are the established volunteers, such as Red Cross/Red Crescent and firefighter volunteers, consisting of volunteers who not only have their capabilities registered in the system, but may also be well trained, equipped, and experienced, with existing communication 
channels. At the other end, spontaneous volunteers exist who, as the name implies, spontaneously take the initiative to help with an emergency response. In daily emergencies, these volunteers are laypersons and bystanders, who are usually closer to the emergency sites than professionals. Between these two extremes another group of volunteers exists, emergent volunteers. This group is composed of more recently developed semi-organized forms of volunteering, where people who usually have some basic trainings are registered, but they do not have any formal responsibilities.

These novel human resources can be utilized in response to different types of medical emergencies, including bleeding, OHCA, and trauma. However, as seen from the literature, the majority of researchers who have studied novel human resources have focused on OHCA as their use case. Most of the studies that have focused on bleeding are related to North America and have been conducted in relation to the "stop the bleed" campaign. This campaign was formed after several incidents in the USA that resulted in mass casualties in which rapid bleeding control was needed.

While EMS are the main contributors to early advanced interventions (e.g., advanced cardiopulmonary resuscitation (CPR)), novel human resources can play an effective role in interventions that require basic training and knowledge. For instance, in the case of an OHCA, early access, early basic CPR, early defibrillation, and early advanced CPR are parts of the "resuscitation chain" that can lead to higher survival chances for OHCA patients (Cummins et al., 1991). Involvement of novel human resources in response to an OHCA can make contributions to the first three parts of this chain, which are all factors associated with an improved survival chance for OHCA patients (Metelmann et al., 2021; Nehme et al., 2019; Pijls et al., 2016; Stroop et al., 2020).

The distinction between volunteers and the two categories of first responders and laypersons and bystanders is quite clear, given their descriptions. However, the line separating volunteers and the category $C F R$ might occasionally be blurred. CFR might have higher level of medical training than (emergent and spontaneous) volunteers, but like volunteers, CFR also volunteer to provide help within their community. Consequently, it is possible to reduce the categories of novel human resources to three classes by categorizing CFR under volunteers forming one single class of volunteers. In this thesis, the term volunteers refers to anyone who registers in operational volunteer programs and might only have basic medical training (e.g., performing basic CPR) or be fully medically trained (e.g., a doctor). With regard to the scope of this thesis, in the remainder of this chapter, a few works focusing only on the management of volunteers are briefly discussed. 


\subsection{Effective utilization of volunteers}

To achieve potential benefits from utilizing volunteers in the emergency management system (e.g., early basic CPR or early defibrillation in the case of an OHCA), several aspects need to be considered in volunteer management. Researchers have focused on volunteers' attraction and motivation, training, integration into operations, evaluation, use of IT-based tools as a means of communication, the effect of bystanders and spontaneous volunteers on emergency outcomes, and task assignment. While most studies on volunteers have focused on the context of disasters, in recent years, the involvement of volunteers in daily emergencies has been increasingly studied and evaluated.

Attraction and motivation of volunteers are important aspects of starting and sustaining an initiative (emergency response volunteer program). Therefore, it is important to determine which factors can affect the attraction and motivation of volunteers, either positively or negatively. Local government agencies play a role in attracting volunteers and managing them, and have an effect on volunteering for daily emergency events (Choudhury, 2010). Therefore, the presence of such information can be helpful for an emergency manager to attract and motivate future volunteers and to retain current ones in the emergency response volunteer programs. On a personal level, "ideas of altruism and a sense of community" (Timmons and Vernon-Evans, 2013) and "altruistic, social and pre-existing emergency care interest" as well as personal experience of cardiac arrest or illness in a relative (Barry et al., 2019) are among the factors motivating people to volunteer. Family issues are another factor affecting the number of rural emergency volunteers; however, this factor results in a decrease in volunteering (Cowlishaw et al., 2008).

A good foundation for the utilization of volunteers is to know what skills and knowledge they have. In the presence of such information, it is possible to employ the right volunteer for the right emergency type, to provide them with relevant and required training, and to develop the right IT-based systems, for both their use and their management. Earl et al. (2003, 2005) focused on outdoor music festivals to study the knowledge and skills of volunteers who participated at those events. Sun and Wallis (2012) focused on training volunteers and provided a first-aid responder system model for response to daily emergencies. Hanssen (2015) described a position tracking system that is being used by volunteer organizations in Norway for rescue and response operations.

Eventually, it is essential to have plans for how to properly integrate volunteers into the existing emergency management system, and then to evaluate them and their effect on the system. By investigating new resources, such as volunteers, and their 
utilization in the emergency response system, it is possible to provide suggestions for improving the integration of these resources into an already existing system (Pilemalm et al., 2013), or to conclude that previously trained volunteers have a greater tendency to participate in response to medical emergencies (Groh et al., 2007).

In the context of daily medical emergencies, volunteers have mostly been studied in response to OHCA, and then to trauma. Most of the works that examine the use of volunteers in daily emergencies mainly focus on evaluating the effects of their involvement based on different measures, such as response times and the survival chances of patients. Many studies have investigated the factors that affect victims of medical emergencies, such as the survival chances of OHCA patients. The works of Larsen et al. (1993), Valenzuela et al. (1997), Waalewijn et al. (2001), and De Maio et al. (2003) are examples of such studies that consider some or all parts of the resuscitation chain and present their findings in the form of survival functions. Some works provide overviews of the systems in European countries (Andelius et al., 2021; Oving et al., 2019; Scquizzato et al., 2020) and in different countries across the world (Valeriano et al., 2021), in which volunteers and first responders are utilized to respond to OHCA cases. Andelius et al. (2021) also presented details of changes in these systems due to the COVID-19 pandemic. This pandemic has led to countries taking different measures in their systems, ranging from a complete halt of the dispatch of volunteers to modifications in the resuscitation protocols employed by volunteers or first responders.

Several researchers have focused on systems for the dispatch of volunteers to daily medical emergencies. Their aim has been either to study the potential of the introduction of such systems in a society or to investigate their effects and functionalities in relation to the dispatch of volunteers. Before starting a volunteer or CFR program, the possibility of the introduction of such a program needs to be investigated, and for this purpose, pilot programs and surveys can be used. Such an investigation in Tochigi prefecture, Japan, indicated that, by providing information to society and the required infrastructural elements, it is possible that a CFR system can be successfully introduced and operated in Japan (Toyokuni et al., 2013). Focusing on a volunteer program for OHCA cases in the Netherlands, Scholten et al. (2011) found several potential focus points, including the alerting process and technical adjustments, to improve the system. Pijls et al. (2019) investigated the activation process of a volunteer alerting system and the activation frequency of the system, showing that, on average, each volunteer was alerted 1.3 times per year, and that the survival of OHCA patients is related to the density of volunteers in a geographical region. 
Currently, volunteer programs alert volunteers through mobile phones using the short message service (SMS) or mobile phone applications (app). A comparison between SMS-based and app-based systems for the dispatch of first responders and volunteers in the canton of Ticino, Switzerland, in cases of an OHCA, showed that the app-based system has been highly efficient in dispatching volunteers and reducing the time to the start of CPR, resulting in higher survival rates (Caputo et al., 2017). Utilizing mobile phones also provides the opportunity of using the mobile-phone positioning system (MPS) as well as the functionality of an app to locate and dispatch volunteers. Considering the OHCA volunteer program in Stockholm, Sweden, Ringh et al. (2015) concluded that the utilization of MPS results in an increase in CPR initiated by volunteers, and Berglund et al. (2018) showed positive potentials in the use of the app to direct volunteers to the scene of an OHCA or to help them locate an AED.

It is always possible to improve an existing system or to use the data in that system to obtain additional information. For this purpose, Ramsell et al. (2019) conducted a meta-analysis and studied the functions that can be used in an app-based system for the dispatch and support of volunteers in response to daily emergencies in Sweden. To determine suitable task assignment prioritization, Auricchio et al. (2019) considered the app-based system reported by Caputo et al. (2017), and investigated the distances traveled by volunteers to reach the patient and to reach the closest AED. By using the tracked position of volunteers throughout their journey to the patient, from the app-based system in Sweden, Jonsson et al. (2020) have estimated the travel speed of volunteers, depending on whether travel was through a densely populated area or not.

It is important to investigate the systems used to dispatch volunteers to determine their levels of functionality, problems, and potential areas for improvement, as well as the information that can be extracted from them. However, it is also important to evaluate the effect of utilizing volunteers in daily medical emergency responses to determine whether their integration into the system contributes to improvements in the outcomes. Such investigations have been conducted by several researchers across the world. Myrick et al. (1983) studied the effect of trained volunteers in medical emergency responses in rural, medically underserved, areas of central Georgia, USA. These authors focused on environmental factors, such as the size of a community, affecting the willingness of people to use a voluntary system for medical emergencies. They demonstrated that communities in which volunteer initiatives were formally established showed greater willingness to use a voluntary system for emergencies than communities in which these initiatives were not formally introduced. Naths et al. (2007) considered two small cities in Germany in 
which volunteers were used for both medical and non-medical emergencies and evaluated the time advantage of using volunteers in response to emergencies. According to the results of their study, in the event of medical emergencies, volunteers had provided primary care for emergency patients and, on average, had a time advantage over EMS. Cairns et al. (2011) developed a Monte-Carlo simulation model to evaluate the effectiveness and cost-effectiveness of using volunteers in response to OHCA in different geographical regions, based on data from several urban and rural regions in Northern Ireland. Through their developed simulation model, they showed that volunteer OHCA initiatives might not be an efficient use of resources in some geographical regions, emphasizing the importance of computer simulations in helping decision-making. Hansen et al. (2015) conducted a study in rural areas of Denmark where homecare providers equipped with AEDs were dispatched to OHCA cases. These authors indicated that homecare providers are suitable human resources to act as community first responders in rural and residential areas, but suggested that their effect on the survival chances of patients should be further studied. Campbell and Ellington (2016) examined the potential benefits of using final- and penultimate-year medical students with training based on the First Person on Scene First Aid standard as CFR in inner-city Birmingham, UK. They showed that the use of trained students as CFR can result in reduced response times. Capucci et al. (2016) studied the project "Progetto Vita" conducted in Piacenza, Italy, in which volunteers were trained to utilize an AED; in case of an OHCA they would only access and utilize publicly available AEDs, and no CPR was performed. They showed that AED-only resuscitation by volunteers had led to an increase in survival rates. Latuska et al. (2019) studied whether or not Stop the Bleed training can be effective in improving the basic knowledge of school nurses in how to control bleeding and apply a tourniquet for this purpose. Through their evaluation, they demonstrated the efficacy of such training for school nurses. To investigate the hypothesis that the simultaneous dispatch of CPR-trained volunteers and EMS is beneficial for the survival of OHCA patients, Stroop et al. (2020) conducted a study in North-Rhine-Westphalia, Germany. They showed that such a scheme has led to a reduction in response times and resuscitation-free intervals that can potentially increase the survival chances of patients. 
Models for Dispatch of Volunteers in Daily Emergency Response 


\section{Research context}

This chapter describes how EMS function as part of the pre-hospital system in Sweden and the Netherlands, countries from which this thesis utilizes volunteer programs as use-cases. It also presents initiatives that utilize novel human resources, such as volunteers, in emergency response in Sweden and other countries to provide a perspective on other use-cases in this research context.

\subsection{Emergency pre-hospital care}

In many countries, emergency pre-hospital care is provided by EMS, which mostly consists of well-equipped ambulances staffed by trained paramedics, emergency medical technicians (EMT), or registered nurses. The goal of EMS everywhere is to save lives of people outside of hospitals, which helps reducing the mortality rate (Aringhieri et al., 2017; Bélanger et al., 2019). Moreover, the structure of EMS in each country may differ from others depending on the rules and legislations that regulate their structures and operations. This section presents the emergency pre-hospital care systems in Sweden and the Netherlands, the two countries from which this thesis has selected volunteer programs and initiatives as use-cases.

\subsubsection{Emergency medical services in Sweden}

According to the Swedish Statistics Central Office (SCB), by the end of 2020 Sweden had more than 10.3 million inhabitants (Swedish Statistics Central Office (SCB), n.d.). With an area of 450,295 square kilometers, it has a low population density of about 23 inhabitants per square kilometer. The southern parts of the country consist mainly of flatland, whereas the middle and northern parts are covered with vast forests and mountains, with less daylight during the winter half of the year, which creates additional constraints for EMS (Langhelle et al., 2004).

With 14 centers across the country, SOS Alarm Sweden AB (henceforth, SOS Alarm), a national, publicly owned organization, is responsible for answering all emergency calls made to the single national emergency number, 112, and alerting the emergency services, including ambulances (SOS Alarm, 2018). After receiving an emergency call and making an initial categorization, SOS Alarm is responsible 
for communicating the required information to the relevant emergency organizations (SOS Alarm, n.d.; Torlén et al., 2017). SOS Alarm has an agreement with the majority of the county councils across Sweden, and for medical emergency calls in those counties, its responsibility extends to prioritizing and dispatching ambulances (SOS Alarm, 2018). In the remaining county councils, the medical emergency calls are forwarded to "Sjukvårdens larmcentral" and the dispatch of ambulances is controlled by these centers (Akademiska Sjukhuset, n.d.-a). It should be noted that the county councils and regions are responsible for providing sufficient ambulances, but SOS Alarm is responsible for their daily use (SOS Alarm, n.d.). In Sweden, besides the ambulances owned by the county councils and regions, other ambulances that are operated by private ambulance companies exist as well (Langhelle et al., 2004). These private companies have contracts with the county councils to provide ambulances (Sören et al., 2016). Medical emergency calls are prioritized according to four grades, from priority 1 assigned to the most urgent and acute life-threatening cases, to priority 4 assigned to planned patient transportation that needs no medical monitoring or assistance (SOS Alarm, n.d.; Steins et al., 2019; Torlén et al., 2017). Ninety-seven percent of the population of Sweden can potentially be reached by an ambulance within 20 minutes, and 80 percent within 10 minutes. However, the time it would take for an ambulance to reach people in rural areas can be longer than 30 minutes (Socialstyrelsen, 2009).

In accordance with a regulation passed in the year 2000 by the Swedish National Board of Health and Welfare (Socialstyrelsen), an organization regulating Swedish ambulance services, every ambulance should have at least one registered nurse on board, and only these nurses are permitted to administer medicines (Socialstyrelsen, 2016). One of the main competences of these nurses is their ability to provide advanced life support (ALS) (Sören et al., 2016). These registered nurses are accompanied by an EMT who can perform basic life support and is only permitted to administer oxygen (Lindström et al., 2015; Sören et al., 2016). Approximately 700 ambulances exist in Sweden (Lindström et al., 2015). Helicopter ambulances are also available in Gothenburg, Stockholm, parts of the northern mountain regions, and part of the Baltic area around Gotland and Stockholm (Langhelle et al., 2004). In addition to regular ambulances, which are staffed by at least one registered nurse, there are also physician-manned ambulances in all Scandinavian countries, including Sweden. The physicians in these ambulances are skilled in anesthesiology, they are accompanied by at least one nurse or paramedic, and such ambulances operate 24 hours a day, seven days a week to deliver critical emergency care (Krüger et al., 2010, 2011). 


\subsubsection{Emergency medical services in the Netherlands}

The Netherlands is a country with an area of about 41,800 square kilometers, of which 33,500 are land. According to Statistics Netherlands (CBS), the country had a population of 17.5 million inhabitants in mid-2021 (Statistics Netherlands (CBS), n.d.), which means that it has a high population density of about 522 inhabitants per square kilometer of land.

In the Netherlands, pre-hospital care is provided by EMS or personal general physicians (GPs). Emergency dispatch centers receive emergency calls through the national single emergency number, 112, and depending on the state of the case, they either dispatch EMS or inform GP of the patient. The GP is informed in cases that the situation is not acute or does not requires hospital intervention (Wulterkens, n.d.). According to Bos et al. (2015), the Netherlands has 25 ambulance care regions and each region has its own Regional Ambulance Service (RAV), which can be publicly or privately owned, and has the responsibility for providing ambulance care in the region. The country has a total of 725 full-time ambulances. In the Netherlands, Ambulancezorg Nederland (AZN) is the national organization for ambulance care and provides services and support to RAVs (Ambulancezorg Nederland (AZN), n.d.). Dispatch of ambulances is region-based and a dispatch center within each RAV manages all emergency and non-emergency medical calls in the region (Bos et al., 2015; Wulterkens, n.d.). However, in accordance with changes suggested in 2010, one single national dispatch organization with 10 local dispatch centers shall be formed, starting in 2020, to manage the dispatch of ambulances in the country (Ambulancezorg Nederland (AZN), n.d.).

In the Dutch emergency system, medical calls are classified into three levels: A1, A-2, and B. Both A-1 and A-2 calls require emergency ambulance transportation, with A-1 assigned to urgent and life-threatening situations that require the presence of an ambulance within 15 minutes, and A-2 assigned to urgent but not lifethreatening calls for which an ambulance should be on site within 30 minutes, while B calls concern non-emergency patient transportation (Bos et al., 2015). Every Dutch ambulance is staffed by two people: (1) a licensed nurse, who is trained in medical situations and the measures and procedures required for handling them and can administer medical treatment independently at ALS level, and (2) a driver, who is trained in vehicle operations and can assist the nurse without interfering medical procedures (Bos et al., 2015; Wulterkens, n.d.). In addition to the usual ambulances, the Dutch emergency medical system is equipped with three other types of resources: (1) motorcycles, which carry the equipment required to start ALS and can act as first responder units, (2) mobile medical teams (MMTs), each of which includes a resident surgeon or an anesthesiologist and a nurse and takes on cases 
where medical needs exceed the medical capacity of regular ambulances, and (3) helicopters with a flight radius of 45 miles covering 80 percent of the country's land (Wulterkens, n.d.).

\subsection{Initiatives utilizing novel human resources}

The aim of presenting initiatives in this section is to show: (1) how these resources are employed in daily emergency responses in practice, and (2) how the models and methods that have been developed can potentially be used for other cases as well as the use-case initiatives in this thesis. Section 3.2.1 is dedicated to describing and detailing initiatives in Sweden. Section 3.2.2 presents the use of novel human resources in various other countries, which have been named in the literature, stating that their initiatives are now operational. It should be noted that because there are only a few Dutch initiatives found in the published literature, these initiatives are also presented in Section 3.2.2.

\subsubsection{Initiatives in Sweden}

As Pilemalm et al. (2013) pointed out: "More than half the geographic area of Sweden can be considered rural, i.e. sparsely populated and taking more than 45 minutes by car to a town with more than 3000 inhabitants." This dispersion of population across the country makes it challenging for emergency services to provide timely aid to everyone. Budget cutbacks can also negatively affect the already limited resources available to the emergency services. To tackle the issues of the lack of sufficient professional resources and long response times to rural areas, several initiatives have begun in Sweden. Some of these initiatives are still in a trial phase, while others have already become operational. In the rest of this section, brief descriptions of some of these projects are presented.

\section{While waiting for the ambulance (I väntan på ambulans (IVPA))}

Starting a few years ago, different municipalities and counties, such as Östergötland (Universitetssjukhuset i Linköping and Katastrofmedicinskt centrum, 2020) and Örebro (Backes, 2020), have implemented a mechanism by which FRS are included in the preparation for response to certain types of medical emergencies. This mechanism is used especially in regions where no ambulance station exists, and where, consequently, it will take longer for ambulance(s) to reach the patients. As in those regions an FRS station does exist, FRS can reach patients more quickly than the EMS, providing help to patients and potentially saving their lives. In this scheme, firefighters receive the required training and equipment from EMS. When a life-threatening medical situation arises, including OHCA, a suspected airway blockage, severe shortness of breath, or life-threatening bleeding, in parallel with 
EMS, FRS are also alerted by the call center. IVPA has then expanded and is also used across the whole municipality or county for OHCA cases, rather than being limited to areas with poor ambulance coverage (Akademiska Sjukhuset, n.d.-b).

\section{SALSA project}

As part of the efforts to reduce response times for OHCA cases and potentially increase the survival chances of patients, in addition to EMS, FRS and the police can be dispatched to these cases (Hollenberg et al., 2009). A trial with the dual dispatch of EMS and firefighters or police officers showed an increase in 30-day survival of OHCA patients (Hasselqvist-Ax et al., 2017; Nordberg et al., 2014, 2015). Nordberg et al. (2015) studied the differences in effect of the dual dispatch of firefighters or police officers between rural and urban areas, because the population densities in these regions differ. Their findings show a significant reduction in response time, regardless of region (i.e., rural or urban), and a significant increase in 30-day survival of patients.

\section{Semi-professionals}

"Semi-professionals" refers to a group of people whose primary occupations are not emergency response. However, with extra training in responding to emergencies, based on their primary profession, they can take on additional responsibilities and provide help within the rescue and response system (Granberg et al., 2017, 2016; Yousefi Mojir and Pilemalm, 2013). To respond to different types of emergencies, however, these semi-professionals need to receive the necessary training, such as performing CPR (Granberg et al., 2017). Examples of this group of people include security guards, building technicians, and elderly care personnel (Granberg et al., 2017). One of the incident types that these semi-professionals can get involved in is OHCA (Yousefi Mojir and Pilemalm, 2013).

\section{Enhanced Neighbors project}

Ramsell et al. (2017) conducted a study on the project Enhanced Neighbors, in which residents in rural areas (e.g., villages) with long distances to emergency services, act as volunteers and collaborate in emergency responses. The types of emergencies to which the volunteers in such regions would respond include OHCA, traffic accidents, drownings, and selected fire incidents. In the event of any of these emergencies, and simultaneous with the dispatch of EMS and FRS, the volunteers receive a notification from the call center and, if possible, will provide assistance.

\section{Civilian response persons (Civil insatsperson (CIP))}

In 2010, a proposal was made to use civilians to help in responding to emergencies in rural areas of Sweden that have poor emergency coverage. The 
rescue and response association of Medelpad used that proposal and implemented it as a project in which private civilians in rural areas would be alerted via text messages (Stenberg et al., 2014). Another operational case of CIP, which started in 2015, is in Västra Sörmland county. According to Brandskyddsföreningen Södermanland and Hallström et al. (2016), in Västra Sörmland county, CIP was started by FRS to provide better help to residents of the county who live a long way from emergency services. In this scheme, ordinary people volunteer to provide help in times of emergencies. These people receive eight hours of training consisting of $\mathrm{CPR}$, first aid, and required actions when a person first arrives at a fire, traffic accident, or drowning incident. In case of an emergency, simultaneously with the dispatch of emergency services, CIPs are alerted through an SMS on their mobile phones.

\section{Missing People Sweden}

The task of looking for missing people is the responsibility of the police (Stenberg et al., 2019). However, after two cases of missing people in 2010 and 2011 in the city of Gothenburg, when the police lacked sufficient resources to look for these people and civilians provided help in doing so, the association of Västra Götaland seekers was founded (Missing People Sweden, n.d.). Later, other parts of the country realized that they could benefit from similar schemes (i.e., civilians who help the police to look for missing persons), and thus, Missing People Sweden was formed in 2012. Currently, Missing People Sweden is active nationwide with about twenty regional departments, and civilians involved in search missions provide assistance on a voluntary basis (Missing People Sweden, n.d.).

\section{SMS lifesavers (Sms-Livräddare)}

SMS lifesavers started in 2010 as a research project in Stockholm, and is now operational in ten counties/regions in Sweden, which also runs nationwide in Denmark (where it is known as TrygFonden Hjerteløber) (Heartrunner Sweden AB, n.d.). Civilians who are familiar with $\mathrm{CPR}$ and the utilization of AED register as SMS lifesavers. These volunteers can contribute to OHCA cases by performing CPR or collecting an AED on their way to the patient. In this initiative, a mobile phone positioning system (MPS) is used to locate volunteers in the vicinity of the patient. Simultaneous with the dispatch of EMS, SMS lifesavers receive an automatically generated notification on their mobile phones (Ringh et al., 2011, 2015). These volunteers, if they accept the primary notification, will be assigned one of two tasks: (1) to go directly to the patient to perform CPR, or (2) to collect an AED en route to the patient. 


\subsubsection{Initiatives in other countries}

Based on the published literature, many countries other than Sweden and the Netherlands have also begun to study the benefits of using volunteers and other novel human resources in their response systems. Examples include Australia, Austria, Belgium, Canada, Chad, Denmark, England, Finland, France, Germany, Guatemala, Iraq, Ireland, Italy, Japan, Kuwait, Madagascar, Malawi, Norway, Republic of Guinea, Singapore, Sierra Leone, South Africa, Scotland, Spain, Sweden, Switzerland, Tanzania, Taiwan, Uganda, United Republic of Tanzania, and the USA. Among these countries, some have already started integrating these new resources into their response systems. In the remainder of this section, initiatives that are already operational in some of these countries are briefly presented.

In the Netherlands, a target of six minutes to first defibrillation after an emergency call has been made for OHCA cases, set by the Dutch Heart Foundation, and a textmessage alert system has been implemented by regional dispatch centers (Zijlstra et al., 2014). In this initiative, a text message is sent to volunteers who are within a 1000-meter radius of the patient, to either perform CPR or collect a nearby AED. This system has now been upgraded to using both text messages and a mobile phone app (Oving et al., 2019). In another initiative, police officers receive training in the use of AED to act as first responders and are dispatched to OHCA patients in both public and private locations (Kooij et al., 2004; Zijlstra et al., 2014).

In Table 1, a few countries where operational initiatives using novel human resources exist are presented. From this table, it can be seen that in the majority of these countries, first responders and volunteers are the novel human resources most often used in the initiatives. Moreover, OHCA is the most common emergency type to which first responders and volunteers are dispatched. 
Table 1. Initiatives in different countries

\begin{tabular}{|c|c|c|c|}
\hline Country & Novel resource & Emergency type & Reference \\
\hline Australia & $\begin{array}{l}\text { First responders } \\
\text { (firefighters) }\end{array}$ & $\begin{array}{l}\text { Life-threatening event } \\
\text { (e.g., OHCA) }\end{array}$ & $\begin{array}{l}\text { K. Smith et al. } \\
\text { (2001), Winship et } \\
\text { al. (2014) }\end{array}$ \\
\hline Denmark & $\begin{array}{l}\text { First responders } \\
\text { (firefighters), } \\
\text { AED }\end{array}$ & $\mathrm{OHCA}$ & $\begin{array}{l}\text { Høyer and } \\
\text { Christensen (2009) }\end{array}$ \\
\hline England & CFR, volunteers & OHCA & $\begin{array}{l}\text { C. M. Smith et al. } \\
\text { (2017), Phung et al. } \\
(2017)\end{array}$ \\
\hline Finland & $\begin{array}{l}\text { First responders } \\
\text { (firefighters), } \\
\text { volunteers }\end{array}$ & $\begin{array}{l}\text { Different medical } \\
\text { emergencies including } \\
\text { OHCA }\end{array}$ & $\begin{array}{l}\text { Tamminen et al. } \\
(2019)\end{array}$ \\
\hline Germany & $\begin{array}{l}\text { First responders, } \\
\text { volunteers }\end{array}$ & $\begin{array}{l}\text { Medical emergencies } \\
\text { (e.g., OHCA) }\end{array}$ & $\begin{array}{l}\text { Gross et al. (2018), } \\
\text { Lichtenhahn et al. } \\
(2019)\end{array}$ \\
\hline Italy & $\begin{array}{l}\text { Volunteers, } \\
\text { AED }\end{array}$ & OHCA & Capucci et al. (2016) \\
\hline Switzerland & $\begin{array}{l}\text { First responders, } \\
\text { volunteers }\end{array}$ & OHCA & $\begin{array}{l}\text { Saner et al. (2013), } \\
\text { Caputo et al. (2017), } \\
\text { Stein et al. (2017) }\end{array}$ \\
\hline The USA & $\begin{array}{l}\text { First responders } \\
\text { (firefighters), } \\
\text { volunteers }\end{array}$ & Medical emergencies & Boland et al. (2015) \\
\hline
\end{tabular}




\section{Research methods}

This chapter includes a short description of operations research as the main research method and a brief presentation of the techniques selected to investigate the problem and address the research questions in this thesis.

\subsection{Operations research}

Since the success of operations research (OR) in solving military operation problems during World War II, OR has been widely and successfully applied in many different (civilian) fields, such as healthcare, public services, transportation, telecommunications, construction, and manufacturing (Hillier, 2010). OR is a wellestablished method with a decision-oriented nature and can provide solutions to complicated decision-making problems using analytical techniques.

Eiselt and Sandblom (2012) describe OR as a discipline that is "concerned with quantitative models and their solution". OR as an empirical science uses mathematics to develop, test, and refine a model of reality and then computerimplement it; nevertheless, mathematics might not be used in all cases (Larson, 2005). Despite the difficulty of briefly defining OR due to its broadness, different OR organizations and researchers agree that OR consists of the use of scientific methods, techniques, and tools for making a well-defined decision. One of the definitions of OR is presented by the Operations Research Society of America:

Operations research is concerned with scientifically deciding how to best design and operate man-machine systems usually under conditions requiring the allocation of scarce resources.

OR takes efficient steps to aid decision-making at the strategic, tactical, and operational levels (Eiselt and Sandblom, 2012), with the aim of improving systems that are often complex (Royston, 2013). Based on the processes considered by Hillier (2010) and Eiselt and Sandblom (2012), the major steps in the development of an OR model are illustrated in Figure 5.

To develop a model using OR, the first step is to recognize and define the problem that will be studied. Initially, these problems are often described vaguely and imprecisely (Hillier, 2010), and therefore, good observation of the relevant system 
is necessary to obtain sufficient information and become familiar with the system. Based on the understanding of the system and the problem definition, the next step is to construct hypotheses and simplify complex systems. These hypotheses help determining the appropriate data to be gathered and modeling technique to be used in the next two stages. The model development is to reformulate the defined problem in a way that is suitable for analysis (Hillier, 2010) and the data is used in the analysis process. Subsequently, depending on the structure of the model, a relevant solution technique is chosen to obtain a solution from the model using the collected data. Next, the results need to be validated to determine whether the model is an adequate representation of the problem. If the results are determined to be reasonable, then the model can be presented to problem owners and stakeholders. Finally, the acceptable model can be implemented in the real world.

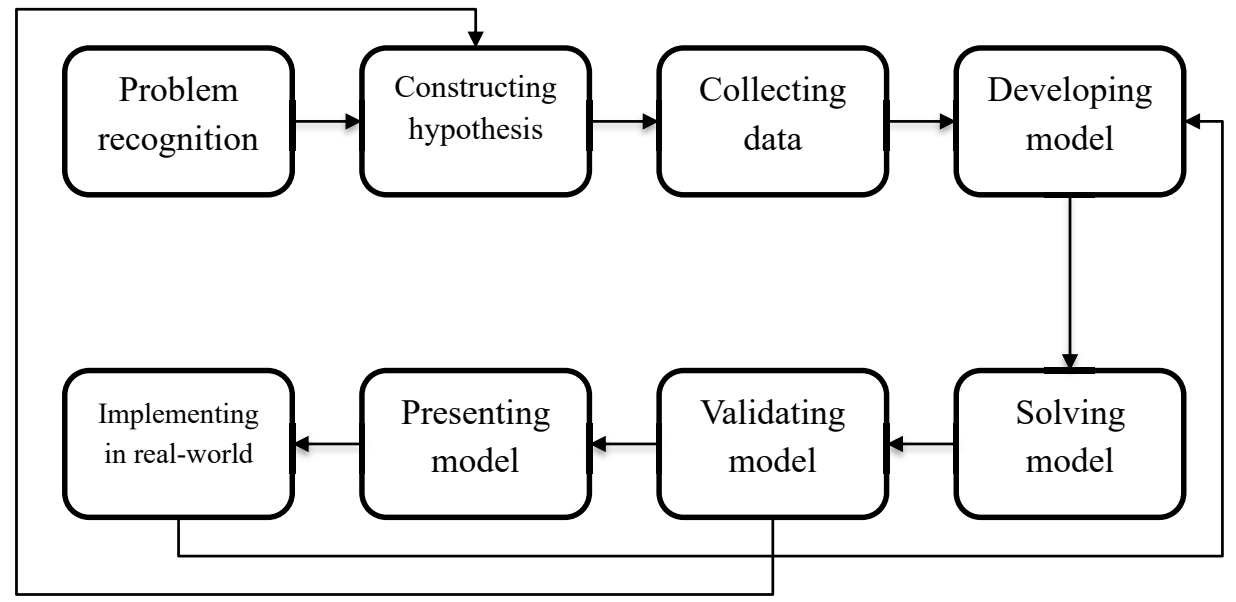

Figure 5. The OR modeling approach

As can be seen in Figure 5, the OR modeling approach has two feedback loops. The first loop is between hypothesis-making and validation steps and the second one is between model development and real-world implementation. The first loop is activated when the obtained results are not useful, and therefore, the initially constructed hypotheses need to be re-evaluated and adjusted. The second loop is used in cases where the developed model no longer reflects the reality in the implementation step, for instance, because the situation (reality) has changed during the modeling process. Under such circumstances, the model will need to be revised, and thus, the feedback loop to the model development step exists. 


\subsection{Choice of techniques}

In OR, different modeling methods and techniques exist, including forecasting, game theory, mathematical programming, queueing theory, and simulation (Hillier, 2010). In this thesis, mathematical programming, simulation, and forecasting are applied. In the following, a general description of the selected techniques are provided based on references such as Hillier (2010), Chen et al. (2011), Banks (2014), Robinson (2014), Law (2015), Sanders (2015). These references can be used for a more detailed and in-depth reading.

\subsubsection{Mathematical programming}

Mathematical programming, or alternatively optimization, is the method for finding the best possible (or an optimal) solution for the mathematically modeled problem. The best possible solution to these models is found based on an objective function and a set of constraints defining the solution space. Different classes of optimization or mathematical programming exist, for example linear (continuous, binary, integer, or mixed integer) programming, nonlinear programming, dynamic programming, and stochastic/probabilistic programming. The decision about the choice of the optimization class depends on the problem structure, consisting of its objective function(s), constraints, and decision variables. Based on the class of the optimization model, different solution techniques are available. For example, mixed integer programming (MIP) models, which consist of continuous and integer decision variables, are solved using techniques such as branch-and-bound, branchand-cut, and decomposition. The goal of modelers and decision-makers is to obtain an optimal solution for the developed model at a reasonable cost and within a reasonable timeframe. However, if the model is too large to be solved in reasonable time using exact methods, heuristic or meta-heuristic methods can be employed instead. These methods are usually efficient at solving the models, and while they do not guarantee an optimal solution, they can find a good suboptimal solution.

\subsubsection{Simulation}

Simulation is a method used to: (1) create a simplified representation of a real complex system to make it easier to analyze, and (2) solve a problem related to that system by using the simplified version. This technique not only manages to model complex systems without too many unnecessary simplifications, but it can also provide a good level of detail to support decision-making. Simulation can model real-world systems; however, it can also be used to model and study non-existing systems, during the design stage and before they are built in reality. It is a good way to answer "what-if" questions without actually making changes to the real-world system, which is also a proper method for testing scenarios and assumptions for a 
non-existent system. Simulation models can imitate the performance of a system or process in reality to assess the actual performance it could have. While it is easy to use and interpret these models, they are capable of dealing with uncertainties within complex systems. Agent-based simulation, discrete-event simulation, Monte Carlo simulation, and system dynamics are different types of computer simulation.

\subsubsection{Forecasting}

Forecasting can be defined as the process of predicting the future or making an estimate of a future event. Apart from the applications of forecasting that everyone uses in everyday life (e.g., estimating the cycling time between two given points), forecasting is used in different sectors such as inventory management, customer sales or product demand, and demand for medical emergency services (Kamenetzky et al., 1982; Matteson et al., 2011). Forecasting models play a critical role in decision-making and planning by considering and managing uncertainties related to the future. Regression models (e.g., linear regression or logistic regression), time series models, and spatial-temporal models are different types of forecasting models. When a forecasting model is developed, its accuracy should be evaluated, and if the required accuracy level is not met, the model needs to be adjusted and examined again. Different accuracy measures exist that can be used to evaluate a forecasting model; mean error (ME), mean squared error (MSE), and mean absolute error (MAE) are examples of such accuracy measures (Hyndman and Koehler, 2006; Mehdiyev et al., 2016). 


\section{Conducted research}

This chapter describes the conducted research and presents the research gap, including the practical and theoretical problems, research questions, the development process of the included papers and a summary of each paper, and the main contributions of the thesis.

\subsection{Research gap}

The literature on novel emergency resources shows that the employment of volunteers and AEDs as additional resources in daily medical emergency responses is beneficial, for example by reducing response times. The reduction in response time can lead to an increase in the survival rates of patients. In addition, the use of systems for volunteer dispatch and task assignment in daily medical emergencies, such as app-based and SMS-based systems, have been shown to be beneficial for the employment and management of volunteers in daily medical emergency response. Nevertheless, the majority of these systems use static strategies to assign tasks to volunteers, as briefly described in studies such as Jonsson et al. (2020) and Slaa (2020), who focused on OHCA volunteer programs. Each of these task assignment strategies is usually designed for a specific volunteer program and considers a particular setting (e.g., the societal or geographical circumstances of a country or region). Due to their static nature, these strategies lack flexibility in applicability to other programs with different settings. In addition, the use of static strategies means that these systems are incapable of accounting for the uncertainties associated with real-life scenarios. Travel times of volunteers and EMS and compliance of volunteers with their assigned tasks are examples of such uncertainties. These rules also lack the capacity to take into account the survival chances of patients (or any other relevant evaluation function) when determining the tasks for volunteers.

In the literature on novel emergency resources, models and methods for the systematic use of some of these resources, such as AEDs, exist (e.g., Bonnet et al. (2015), Chan et al. (2016), Chan et al. (2018), and Lee et al. (2019)). However, a noticeable lack of such models and methods for other types of novel emergency resources, such as volunteers, exists. Despite the significant number of operational 
volunteer programs around the world, published models or methods for the systematic use of volunteers, such as their dispatch or task assignment in daily emergencies, are nonexistent. There are studies that have developed models for the task assignment of volunteers related to disasters (e.g., Falasca and Zobel (2012) and Lassiter et al. (2015)); nonetheless, the number of such studies are also few. There is a rich literature on planning and logistical problems relating to traditional resources, where many researchers have developed models and methods using OR to address these problems. Reviews by Aringhieri et al. (2017) and Bélanger et al. (2019), for example, present overviews of a number of such studies concerning EMS. Even though such a rich literature on models for EMS exists, the differences between volunteers and EMS makes it impossible to directly use such models for volunteers (even with minor modifications). Examples of differences between these two types of resources are the certainty of availability of EMS and the presence of sufficient knowledge about the existence of their fleets, in contrast to uncertainties about the availability and actions of volunteers. In addition, at the time of dispatch of emergency fleets, and once at the scene of the emergency, they will follow their guidelines and protocols, and therefore, no task assignment is needed. However, volunteers need to be told what task to perform to help in an emergency. Thus, a need for models and methods specifically designed for volunteers exists.

The development of smarter and more dynamic dispatch models, methods, and strategies can improve the benefit level of volunteer programs. Despite the potential benefits that can be gained from the incorporation of survival functions in decisionmaking for daily emergency management, few studies have utilized such functions (e.g., Erkut et al. (2008)). Models for volunteer management in daily medical emergencies that consider uncertainties, such as the compliance of volunteers, and utilize a survival function are the missing pieces in the existing studies. Such models can be beneficial for volunteer programs in practice by helping to save more lives and reduce the amount of damage and loss.

In current $\mathrm{OHCA}$ volunteer programs, AEDs are placed in fixed, public locations and someone, such as a volunteer, needs to fetch them. This requirement means that the person(s) picking up these devices will generally need to travel longer distances, deviating from their direct route to the patient. This will naturally translate to longer travel times via AEDs compared to direct travel times, which can lead to a reduction in the benefits of the use of volunteers and AEDs. Consequently, the idea of mobile AEDs has been introduced as a novel solution to decrease the time to delivery of these devices. Different trials have started focusing on the delivery of AEDs to the incident site using different modes such as drones, taxis, and privately-owned vehicles. In the case of privately-owned vehicles, cars are equipped with AEDs and 
their owners are registered as volunteers; in case of an OHCA, these volunteers will go directly to the location of the patient to deliver and apply their AEDs. Nevertheless, the trials using mobile AEDs also rely on static task assignment rules, which have the shortcomings already mentioned. Moreover, no published advanced and dynamic models and methods for the dispatch of volunteers and task assignment to them that include mobile AEDs can be found in the literature.

\subsection{Research questions}

Based on the identified research gap, the following research questions (RQs) are presented.

RQ 1. Which new types of resources can be used in emergency medical response and what are their applications?

RQ 2. How can the problem of dispatch and task assignment to volunteers be mathematically formulated and solved to achieve the best possible volunteer utilization?

RQ 3. How can models and strategies for task assignment to volunteers better reflect an uncertain reality?

RQ 4. How can mobile AEDs help improve the current volunteer programs?

RQ 5. How can the demand for emergency resources be predicted and how can factors affecting this demand be determined?

\subsection{Research development}

Figure 6 illustrates the relationship between the included papers and each of the research questions. The six included papers are categorized into two groups of novel emergency resources and emergency resources, where five of these papers focus on novel emergency resources and the sixth paper focuses on the forecasting of required emergency resources.

Paper I presents an overview of novel human resources (e.g., volunteers) as well as the equipment items that are (or can be) used prior to the arrival of EMS to provide help to patients in daily emergencies. Therefore, this paper has an overarching position in relation to the other papers, providing background to the context of novel emergency resources. To obtain the overview presented in Paper I, a thorough literature search was conducted in which journal articles and conference proceedings with medical perspectives were also considered as potential candidates. The results of medical studies have already had an impact on the development of OR models, and can thus, can be used as motivations for these models, such as the inclusion of a survival function in ambulance location models. Therefore, medical studies, when 
meeting the required criteria, were included in this paper to provide a comprehensive review and to illustrate the potential directions for the development of OR models and methods.

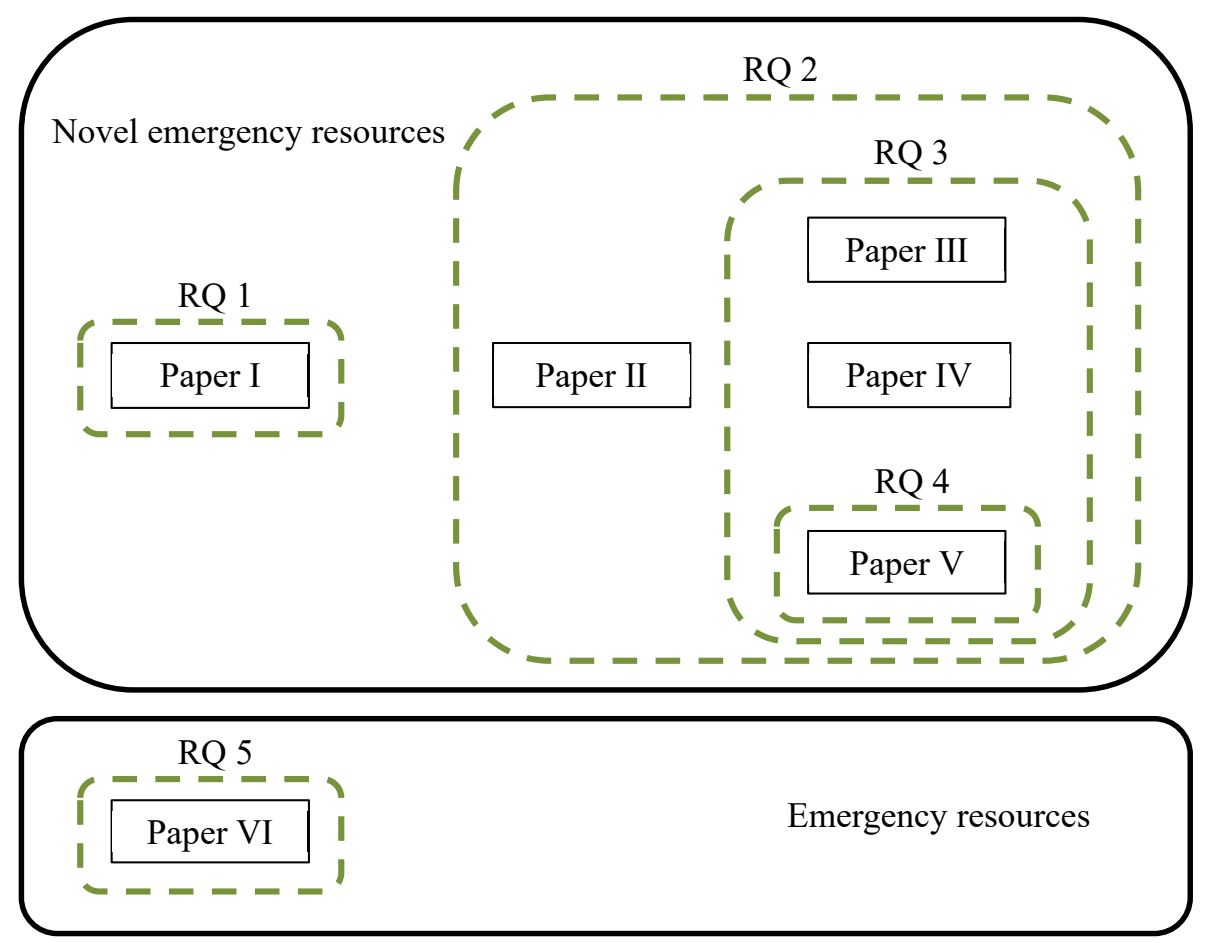

Figure 6. Relation between the research questions and the included papers

Papers II-V propose OR-based models, methods, and strategies for task assignment to volunteers and dispatching them to OHCA patients using data from operational volunteer programs in Sweden and the Netherlands. Despite the similarities in the overall problem addressed by Papers II-V, each of these papers has its own unique aspects that distinguishes it from the others. In Paper II, a deterministic model is developed (i.e., all aspects, such as alert acceptance and task compliance of volunteers, the availability of AEDs, and travel times of volunteers and EMS, are deterministic). In this paper, the arrival gap between volunteers, which can affect the quality of CPR given by volunteers, is included as one of the objective functions of the model. In Paper III, to determine task assignments after volunteers have accepted the alert (online assignment), the uncertainty of task compliance by volunteers is considered. Paper IV develops a model for task assignment and, similar to Paper III, the uncertainty of task compliance by volunteers is included. However, Paper IV determines the task assignment before the broadcast of an alert (offline 
assignment), taking into account the uncertainty of acceptance of the alert by volunteers, and calculating expected travel times for each task. In Papers II-IV, in the proposed models, all AEDs were in fixed positions and their availability was deterministic, and travel times of EMS and volunteers were also deterministic (excluding the further analysis in these papers using simulation). In addition, in neither of the proposed models in these papers, bystanders and their potential contribution were directly included. In Paper V, both fixed-location and mobile AEDs, as well as bystanders, are considered, where mobile AEDs and bystanders have probabilistic availabilities. Moreover, the travel times of both volunteers and EMS are modeled probabilistically. The inclusion of more uncertain elements enables the developed models to better depict the inherent uncertainties of the problem. However, such changes result in more complex settings, which makes the modeling and their solutions more difficult and complicated.

In Paper VI, a forecasting model for the prediction of emergency calls was developed. In this paper, two main sets of data were used: (1) historical anonymized ambulance call data that have resulted in the dispatch of at least one ambulance, and (2) data from the Statistics Sweden database, the Swedish national road database, and OpenStreetMap, which were all large datasets. The initial data processing, including cleaning and integrating different datasets, was conducted using Stata software. The integrated datasets were then mapped to required geographical zones using the GIS software ArcMap. Then, additional data processing and development of several primary test models was conducted using R/RStudio. As it was concluded that models such as linear regression are incapable of modeling the data, a thorough investigation of other possible modeling techniques was undertaken. Eventually, the proposed model was developed using Stata software. The developed forecasting model, alongside additional information about factors influencing the number of emergency calls, has the potential to support models and methods for volunteers and other novel emergency resources.

In Figure 7, details of Papers I-VI are presented. Paper I is placed on top to illustrate its overarching position in relation to Papers II-V. Within the volunteer management box, an italic blue font is used to show the elements that have changed among Papers II to V. Paper VI appears under the volunteer management box in Figure 7 to demonstrate the bottom-up support provided by this paper for this novel emergency resource. 
- Review of papers published in OR/OM and medical journals and conference proceedings

- Application of novel human resources (e.g., volunteers) and equipment prior to the arrival of EMS

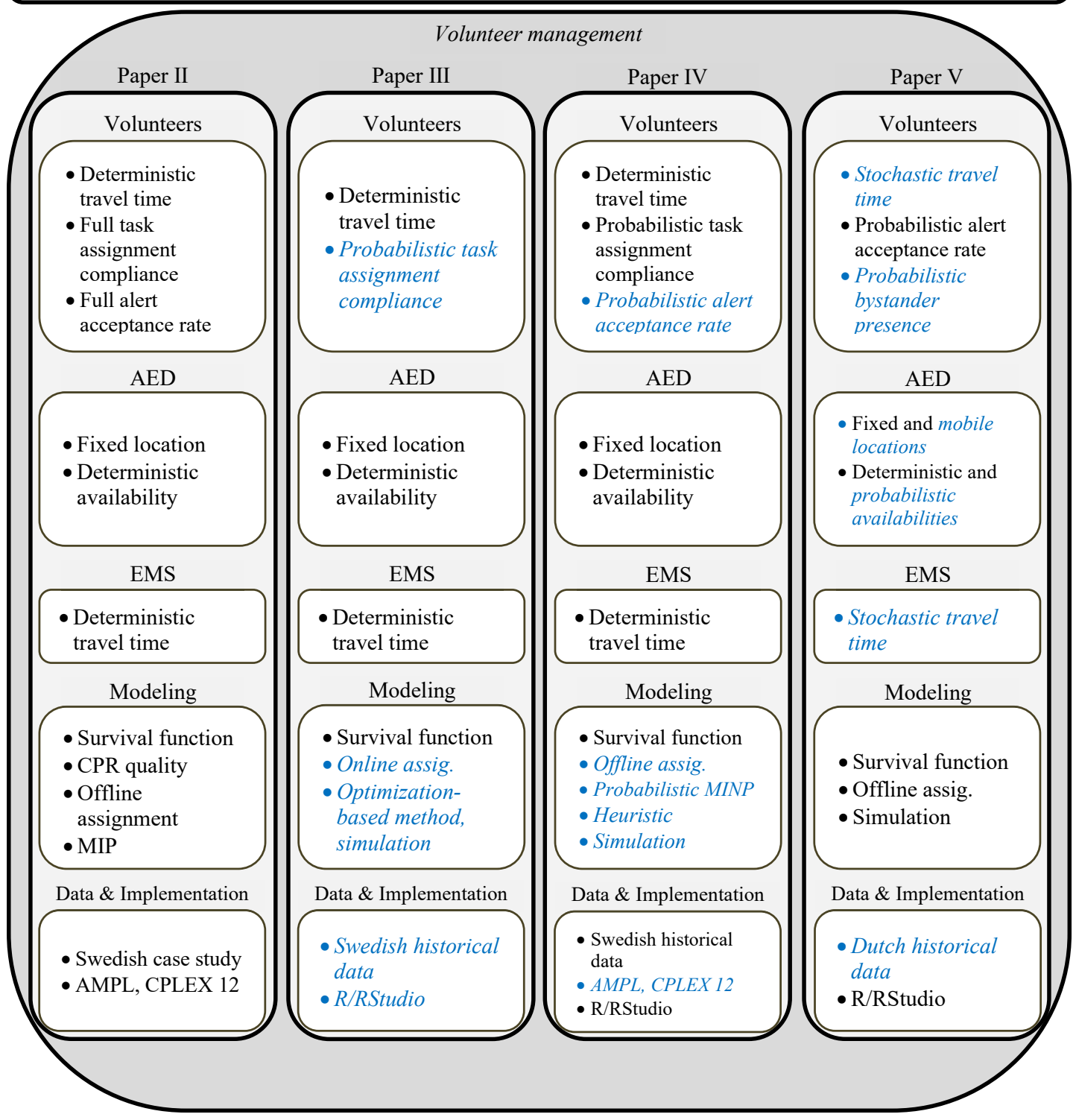

Paper VI

- Forecasting model (Zero-inflated Poisson (ZIP) regression) for the prediction of demand for ambulance calls

- Use of demographic and behavioral factors on a fine scale level of time and geographical zones

Figure 7. Overview of the included papers and their important aspects 
From the papers within volunteer management in Figure 7, Papers III-V have used historical anonymized dispatch data from volunteer programs in Sweden or the Netherlands, and Paper II has used data from a single case study in Sweden. The datasets used in Papers III-V are relatively large requiring extensive data processing work to clean them as well as to draw required parameter values or distributions for the different required elements. All the data processing for these papers was carried out using $\mathrm{R}$ programming language (henceforth referred to as R, including in Figure 7) and its integrated development environment, RStudio.

The proposed MIP model in Paper II was implemented in AMPL and solved to optimality using CPLEX 12. In Paper III, both the optimization-based method and simulation were implemented in R/RStudio. To implement the simulation in this paper, estimated real travel speeds were required, which were extracted using the existing tracked positions of volunteers. Nevertheless, as the available positions are approximate, a thorough investigation of these estimates was conducted to ensure that the estimates were made properly. R/RStudio was also used for the simulation implementation in Paper V. However, several parameter values were not available in the dataset; thus, they were found through a literature search. The reported values in these works were mostly single values rather than distributions. To fit proper (triangular) distributions to these values, from which random values could be drawn in simulation replications, a thorough calibration was conducted. The calibration process was also conducted using R/RStudio.

Similar to Paper II, the optimization model in Paper IV was implemented in AMPL. However, the model developed in Paper IV is a mixed integer nonlinear programming (MINP) model. Therefore, the nonlinear solver "MINLP" on the NEOS server (NEOS Server, n.d.) was used to test this model on a number of cases from the dataset. At the time of this study, none of the nonlinear solvers could guarantee a global optimal solution for non-convex models. Thus, the MINP model was first linearized; then, the linearized model was implemented in AMPL and was solved to optimality using CPLEX 12. However, with respect to the growing size of the model, it was impossible for AMPL/CPLEX to solve the linearized model with many volunteers; consequently, a heuristic was designed. The proposed heuristic and the simulation were both implemented in R/RStudio. 


\subsection{Summary of papers}

In this section, a summary of the six included papers is presented.

\subsubsection{Paper I: A review on initiatives for the management of daily medical emergencies prior to the arrival of emergency medical services}

Paper I presents a comprehensive review of new types of resources that are utilized in daily medical emergency responses prior to the arrival of EMS, consisting of human resources (e.g., volunteers) and equipment (e.g., drones). In this paper, these resources are referred to as "pre-EMS services". In this review, we considered different aspects of pre-EMS services, including medical, technical, and logistical. With the focus on daily medical emergencies, studies from operations research/operations management as well as medical journals and conference proceedings are included. Researchers utilized both qualitative and quantitative methods in these papers. The review includes 258 papers within a time span of 39 years (1982-2020) providing a macro-level analysis of the included papers rather than a detailed analysis of a few individual papers.

Our analysis of the literature included in this paper shows that the majority of studies focusing on human resources belong to the field of medical research. These studies have been conducted using methods common to the medical research area, such as real-life experiments, retrospective studies, and prospective studies, as well as other qualitative methods (e.g., surveys). Prior to 2019, no paper has used quantitative methods, such as optimization or simulation, to develop models for the dispatch and assignment of tasks to volunteers. On the other hand, more studies focusing on equipment have used quantitative methods, such as optimization and simulation. Nevertheless, in overall, a relatively low number of studies have utilized quantitative methods across all pre-EMS services. Moreover, in most studies, the researchers have focused on only one or just a few types of pre-EMS services for specific types of emergencies. In addition, some types of emergencies are studied mostly in relation to a specific region/continent. For example, the majority of studies focusing on bleeding are related to North America, which stem from the "stop-thebleed" campaign.

Paper I was written in collaboration with Melanie Reuter-Oppermann. The author of this thesis was the main contributor to the paper. The contributions included involvement in the conceptualization of the paper and the primary literature search for the entire paper as well as a detailed literature search on human resources. Furthermore, it included designing the layout and major involvement in the writing of the paper.

Paper I is published as: 
- Matinrad, N., and Reuter-Oppermann, M. (2021). A review on initiatives for the management of daily medical emergencies prior to the arrival of emergency medical services. Central European Journal of Operations Research, 1-52.

Parts of the work were presented by the author of this thesis at:

- 46th Annual Meeting of the EURO Working Group on Operations Research Applied to Health Services (ORAHS), online, July 26-31, 2020.

\subsubsection{Paper II: Optimal dispatch of volunteers to out-of-hospital cardiac} arrest patients

Inspired by the setting of the SMS lifesavers project (https://www.smslivraddare.se/), one of several projects utilizing semi-organized volunteers across the world, in Paper II we proposed a deterministic MIP model for the dispatch of volunteers to OHCA cases. In this project, volunteers are assigned one of the two tasks of: (1) going directly to the patient and performing CPR or (2) picking up and delivering an AED to the incident site. In the model, we assumed that all notified volunteers would accept the call, and all other factors, including the arrival times of the EMS and the travel times of volunteers, were also deterministic. The proposed model is multi-objective, with the maximization of the survival chance of the patient serving as its main objective. Factors affecting survival chances are "time to start of defibrillation", "time to start of CPR", and "quality of CPR". The model determines the total number of required volunteers and the task assignment for each of the selected volunteers to achieve the shortest possible times to start of defibrillation and start of CPR. We modeled the quality of CPR in the form of arrival gaps. Therefore, the model selects volunteers in a manner such that no gap between the arrival of each pair of consecutive volunteers shall exist, and thus, the patient receives consistent CPR of the required quality until either an AED or EMS arrives.

Using the weighted sum method, we transformed the proposed multi-objective model into a single-objective one and solved it. We tested the model on the data obtained from a case study, which was conducted in the municipality of Norrköping, Sweden. The case study, consisting of 174 cases, included a set of potential first responders equipped with a smartphone app to receive alerts that they could either accept or decline. We also compared the model against two greedy dispatch approaches that were inspired by the literature: (1) always prioritizing dispatch to the patient, and (2) always prioritizing dispatch to pick up an AED. The comparative results indicate that the proposed model performs better than both of these greedy approaches, resulting in higher survival rates for the patient in 80 percent and seven 
percent of the tested cases, respectively. Moreover, according to the results, in 13 percent of the tested cases, the proposed model and both greedy approaches produce the same survival rates. The dispatch decision directly affects the life or death of the patients; thus, it is reasonable to consider the seven percent of tested cases where the second greedy approach failed to produce an optimal solution. The optimization model, unlike a static rule, can take the circumstances of each case into account and suggest a dispatch decision that maximizes the survival chances of the patient.

Paper II was produced in collaboration with Tobias Andersson Granberg, Nicklas Ennab Vogel, and Vangelis Angelakis. As the main author of the paper, the author of this thesis carried out the literature review, developed the preliminary model, refined the final model, implemented the model, analyzed the results, and had major involvement in the writing of the paper.

Paper II is published as:

- Matinrad, N., Granberg, T. A., Ennab Vogel, N., and Angelakis, V. (2019, January). Optimal Dispatch of Volunteers to Out-of-hospital Cardiac Arrest Patients. In Proceedings of the 52nd Hawaii International Conference on System Sciences.

Parts of the work were presented by the author of this thesis at:

- 44th Annual Meeting of the EURO Working Group on Operations Research Applied to Health Services (ORAHS), Oslo, Norway, July 29August 3, 2018.

- Swedish transport research conference 2018, Gothenburg, Sweden, October 15-16, 2018.

\subsubsection{Paper III: Modeling uncertain task compliance in dispatch of volunteers to out-of-hospital cardiac arrest patients}

Paper III extends Paper II by explicitly modeling uncertainties associated with the actions of volunteers once they have been assigned a task. We did this by considering the probabilities of mission abort, non-complying actions, and full compliance with instructions for each task assignment. This consideration was included to provide a more realistic approach for the dispatch of volunteers than that employed in Paper II. Thus, in this paper, we developed an online method to dynamically assign a task to each volunteer once they have accepted the alarm. We incorporated a survival function into the model and considered all the possible outcomes resulting from the actions of volunteers.

We compared the proposed method with the dispatch approach used at the time of this study by the SMS lifesavers project, as stated by the project team. Of 707 
anonymized historical cases in the dataset (May-September 2018), we considered 663 cases in which at least one volunteer had accepted the alarm. The comparative results indicate that, in 90 percent of cases, the proposed method performed better than the original dispatch method used by the SMS lifesavers project. In these cases, the largest difference in their achieved survival chance is 0.113 . In four percent of cases, the original method performed better than the proposed method, and the largest difference between their achieved survival chance is 0.024 . In the remaining six percent of cases, both methods performed equally well. We used simulation to validate our results and to include additional stochastic factors, such as travel times, which were impossible to directly include in the proposed method. The results of the simulation indicate that the proposed method performs better than the original method in 71 percent of cases, showing a drop of 19 percentage unit from the analytical results. Moreover, we performed sensitivity analyses on EMS arrival time, probabilities, survival function, route distances as opposed to Euclidean distances, travel time model, and bystander CPR. Considering the mean of the differences in survivability between the two methods, which was 0.015 in the 663 cases, by using the proposed method, 10 more people, on average, will survive compared to when the original dispatch method is used. Since the 663 cases spanned a period of about four months, the use of the proposed method would translate to saving potentially 30 more lives per year in Sweden using a dynamic dispatching method.

Paper III was implemented in collaboration with Tobias Andersson Granberg and Vangelis Angelakis. The author of this thesis was the main contributor and was involved in the conceptualization of the paper as well as the modeling, carrying out the literature review, conducting the coding, and implementing the method and the simulation. This author also performed the entire sensitivity analyses, analyzed the results, and had major involvement in the writing of the paper.

Paper III is published as:

- Matinrad, N., Granberg, T. A., and Angelakis, V. (2021). Modeling uncertain task compliance in dispatch of volunteers to out-of-hospital cardiac arrest patients. Computers \& Industrial Engineering, 159, 107515.

Parts of the work was presented by the author of this thesis at:

- 45th Annual Meeting of the EURO Working Group on Operations Research Applied to Health Services (ORAHS), Karlsruhe, Germany, July 28-August 2, 2019. 


\subsubsection{Paper IV: Optimal pre-dispatch task assignment of volunteers in daily emergency response}

In some volunteer programs, such as SMS lifesavers, volunteers can indicate their availability by using a mobile phone application (app); thus, task assignment is done after the volunteers have indicated their availability. However, in other programs, like Enhanced Neighbor in Sweden, volunteers are notified through SMS, and they do not always reply to the notification messages. Therefore, in such programs, task assignment should be completed prior to the broadcast of a notification message. In Paper IV, we focused on the problem of task assignment to volunteers in daily emergencies. However, in contrast to Paper III, we considered task assignment before dispatch, that is, assignment of tasks to the volunteers prior to the broadcast of the primary notification. In Paper IV, we developed an optimization model for this purpose and used OHCA as a use-case to test the developed model. In this paper, in addition to the uncertainties considered in Paper III (probabilities of mission abort, non-complying actions, and full compliance), we also included the probability that volunteers would accept the initial notification.

We developed a MINP model to assign a maximum of one task to each volunteer in an emergency, maximizing the benefits of the volunteer response. In this model, for each task type, we considered a priority set based on the travel times of volunteers to the task location; we used these sets to calculate the expected travel time of the first response. In the event of an OHCA, this translates to two priority sets: (1) travel times of volunteers contributing to the start of CPR, and (2) travel times of volunteers bringing an AED to the patient and starting defibrillation. We linearized the model and solved it using an existing commercial linear solver, CPLEX, to obtain exact solutions to the model. We constructed a heuristic to solve larger problem instances (in our use-case, instances with more than seven volunteers). We used the data from the SMS lifesavers program as our use-case. We compared the performance of the heuristic with the optimization model, showing that the heuristic can produce optimal or near-optimal solutions and can therefore be considered a reliable replacement for the model for larger instances. Then, we compared the performance of our model, using the heuristic, with two task assignment strategies used in OHCA volunteer programs, as reported in the literature. The comparative results of the heuristic and the task assignment methods for the SMS lifesavers project and the Dutch OHCA volunteer project (HartslagNu, https://hartslagnu.nl/) show that the heuristic performs better than both methods in 71 percent and 69 percent of the simulated cases, resulting in 0.0826 and 0.0887 higher survival chances, respectively. The better performance of the heuristic compared to the SMS lifesavers project indicates that a smarter method, which 
determines task assignment prior to acceptance and considers uncertainties, can be more beneficial than a static strategy that assigns tasks after acceptance.

Paper IV was co-authored with Tobias Andersson Granberg. Both authors contributed to the conceptualization, modeling, and validation of results. The author of this thesis carried out the literature review, implemented the model, conducted the coding and implementing the heuristic and the simulation, and had major involvement in the writing of the paper.

Paper IV is submitted for publication.

\subsubsection{Paper V: Improving volunteer response to out-of-hospital cardiac arrest using mobile automated external defibrillators}

Considering the same problem context as Papers II-IV, Paper V focuses on the development of strategies for the dispatch of volunteers to OHCA patients while considering non-stationary AEDs in the system. In Papers II-IV, the assumption regarding AEDs was that these devices were positioned in public, stationary locations and volunteers had to go to those locations, pick AEDs up, and deliver them to the incident site. Moreover, their availability was also considered to be known. Currently, in the Netherlands the possibility of including mobile AEDs in the HartslagNu project is being investigated. In this trial study, a number of privately-owned vehicles are equipped with AEDs (henceforth referring to these volunteers as mobile AEDs) that can be delivered directly to the site of an OHCA case as an addition to the current HartslagNu system. In Paper V, we used simulation and proposed dispatch strategies based on the HartslagNu system while analyzing the effect of the mobile AEDs as well, taking into account the survival probability of patients.

In Papers II-IV, in the proposed models, the travel times of EMS and volunteers were modeled as deterministic. In Paper V, we included these travel times as probabilistic, modeling them based on a distribution function (for EMS) and in the form of different modes of transportation (and thus, speeds, for volunteers). Moreover, while the availability of fixed-position AEDs is considered deterministic, in this model we accounted for the uncertainty regarding the availability of mobile AEDs, in the same way as for regular volunteers. As reported by several medical studies, in many OHCA cases, the first CPR or defibrillation is undertaken by bystanders. Therefore, in Paper V, we also considered probabilistic bystander CPR. Similar to Paper IV, in this paper we considered a system in which task assignments are made before dispatch, and thus, the model selects the volunteers and their task assignments prior to the broadcast of the primary notification. 
We determined a number of parameters required for the simulation using anonymized data on the dispatches of volunteers (between March 2019 and February 2021, including 22,808 cases), which we received from the research and development group in charge of the HartslagNu system. The values for other required parameters were extracted from the literature and were fitted to triangular distributions through calibration. We first ran the simulation for the current task assignment strategy under two settings: (1) without the mobile AEDs in the system, and (2) with the mobile AEDs in the system. The results show that the performance of the system with and without mobile AEDs is similar, mainly due to the very small number of mobile AEDs in the trial. Then, we investigated potential improvements by including additional mobile AEDs, considering that a proportion of regular volunteers will instead be mobile AEDs. To change a percentage of regular volunteers to mobile AEDs we considered two alternatives: (1) from the randomly selected regular volunteers to be mobile AEDs only those who would travel by a car would be mobile AEDs, and (2) the volunteers randomly selected to be mobile AEDs could travel to the scene with any mode of transportation (e.g., bike, on foot). The results show that both of these changes lead to increases in the average survival rate of patients. For example, if we consider that 40 percent of regular volunteers will be instead mobile AEDs, in the first and second alternatives, the survival rate increases by two percent and four percent, respectively. Such increases would translate to saving 38 and 87 more lives per year in the Netherlands, respectively. We then tested a different dispatch strategy that led to an improvement in the estimated survival rates. In the proposed alternative strategy, we compared the distance of volunteers to the patient (direct distance) with their total distance to the patient through the AED closest to them (total AED distance). When the total AED distance is smaller or equal to twice the direct distance, the volunteer is assigned to pickup an AED, otherwise, the task assignment is to travel directly to the patient to perform CPR. The results show that the estimated survival rates using the alternative dispatch strategy results in an an increase of survival probability by one percent, which would translate to saving 15 more lives per year in the Netherlands.

Paper V resulted from a collaboration with Derya Demirtas and Tobias Andersson Granberg. The author of this thesis was the main author of the paper and was involved in developing the improved dispatching strategy, carrying out the literature review, conducting the coding and implementing the simulation models, testing and analyzing the results, and had major involvement in the writing of the paper.

Paper V is a working paper. 


\subsubsection{Paper VI: Forecasting the demand for emergency medical services}

Paper VI presents a forecasting model to predict priority 1 and 2 medical emergency calls (acute cases) in three counties in Sweden. The aim of the model was to predict the number of calls for ambulances, per hour and geographical grid zone, in each of these counties. To achieve this aim, the factors affecting the number of emergency calls were first investigated, and then the forecasting model was developed. This led to two contributions: (1) the development of a forecasting model that can be used to better manage existing resources (both traditional and volunteers), and (2) the acquisition of information about factors that play a significant role in the generation of emergency calls that could be beneficial in preventive planning.

The primary dataset consists of anonymized historical data on ambulance calls during years 2013 and 2014 for three counties in Sweden, which was obtained from SOS Alarm Sweden AB. This organization is responsible for managing the majority of ambulance resources in Sweden. Since the developed model was to be compared with an operational forecasting model already used by SOS Alarm that produces predictions for spatial grid zones, we mapped the ambulance call data to the same spatial grid zones. Then, we aggregated the data with different relevant factors, such as socio-economic factors. The variable that was being predicted in this study was count data (i.e., the number of emergency calls), and the final dataset (after all processing steps) contained excessive zeros due to its structure and was not overdispersed. Thus, we used Zero-Inflated Poisson (ZIP) regression to develop the model. Consequently, we developed separate ZIP models with the same set of predictors for each of the three counties. The ZIP model considered both temporal and spatial factors in addition to other explanatory factors. The model could also handle geographical zones that have no population or have a very low call volume, which is difficult with other types of models.

We compared the three models, one model per each county, with the existing forecasting model that is used by SOS Alarm. We used mean error (ME), mean absolute error (MAE), and root mean squared error (RMSE) to compare the performances of the ZIP model and the existing model. The results show that the model described in this paper performed better than the prediction model currently used by SOS Alarm. In addition to performance improvement, the ZIP model provided information about factors that influence the number of calls, which the current model is not capable of. For instance, the results indicate that an older population (65-100) generates more ambulance calls among all age groups. On the other hand, factors such as birthplace and employment rate did not have any 
significant effect on the number of calls for ambulances, and thus, were removed from the final model.

Paper VI was co-authored with Krisjanis Steins and Tobias Andersson Granberg. The author of this thesis carried out the literature review, the preliminary statistical analysis, and a few interviews, and also participated in data processing, the final statistical analysis, and the writing of the paper.

Paper VI is published as:

- Steins, K., Matinrad, N., and Granberg, T. A. (2019, January). Forecasting the demand for emergency medical services. In Proceedings of the 52nd Hawaii International Conference on System Sciences.

Parts of the work were presented by the author of this thesis at:

- 43rd Annual Meeting of the EURO Working Group on Operations Research Applied to Health Services (ORAHS), Bath, UK, July 30August 4, 2017.

- 2017 Swedish Operations Research Conference (SOAK), Linköping, Sweden, October 19-20, 2017.

\subsection{Research contributions}

This thesis makes the following contributions to answer the research questions (RQs):

RQ 1. Which new types of resources can be used in emergency medical response and what are their applications?

- Comprehensive overview of the literature on novel emergency resources (Paper I).

Human resources and equipment that are currently used across the world in daily medical emergency responses and documented in the literature were identified. Use-cases of these resources and the methods used for studying them were shown, and research gaps related to these resources were determined.

RQ 2. How can the problem of dispatch and task assignment to volunteers be mathematically formulated and solved to achieve the best possible volunteer utilization?

- A deterministic, multi-objective, mixed integer programming model for the dispatch of volunteers to OHCA cases, using a survival function as the main objective function (Paper II). 
The model considers both the survival of the patient and the quality of $\mathrm{CPR}$, a factor not considered in any previous model. The model can be used as a basis for new dispatch systems where prior information or data on the performance of volunteers or the response system, such as acceptance rate by volunteers or response times of EMS, is insufficient or unavailable.

- A sequential probabilistic method for the dispatch of volunteers to OHCA patients after each volunteer accepts the initial notification (an online, dynamic method) (Paper III).

The method uses a survival function to make task assignment decisions, taking into account at each stage the previously assigned tasks and potential actions of volunteers in relation to their task assignments.

- A mixed integer nonlinear programming model (Paper IV) and a discrete-event simulation model (Paper V).

The models and strategies assign tasks to volunteers before dispatch that can be used in volunteer programs in which volunteers do not indicate availability (i.e., they do not respond to the initial notification).

RQ 3. How can models and strategies for task assignment to volunteers better reflect an uncertain reality?

- Inclusion of uncertainties related to acceptance of the alert by volunteers (Papers IV and V), task compliance of volunteers (Papers III and IV), travel times of volunteers (Papers III-V), EMS response time (Paper V), bystander CPR (Papers III and V), and the availability of mobile AEDs (Paper V) in the proposed models.

- Development of new models, methods, and strategies, considering different uncertain aspects that are inherent in the problem, and evaluating the survival chances of patients, the most important health outcome, using optimization and simulation (Papers III-V).

By means of these models, methods, and strategies it was shown that the use of OR and consideration of several uncertain elements in task assignment to volunteers may be beneficial compared to the simple, static rules currently used by volunteer programs.

RQ 4. How can mobile AEDs help improve the current volunteer programs? 
- A thorough study of the benefit of including mobile AEDs in a volunteer program, showing the potential for improvement of survival rates for patients by inclusion of the mobile AEDs (Paper V).

The investigation illustrates the relation between the inclusion of more mobile AEDs and higher survival rates.

- An investigation of different task assignment and dispatch strategies considering both mobile and fixed-position AEDs (Paper V).

An alternative dispatch strategy, tested on different rates of mobile AEDs, that led to improvements in survival rates was proposed.

RQ 5. How can the demand for emergency resources be predicted and how can factors affecting this demand be determined?

- A forecasting model to predict the number of emergency calls requiring assistance of emergency medical services (Paper VI).

The model makes the forecast at a fine temporal and spatial level, considering demographic and behavioral factors, such as the age of people, and when and where they go to dine or shop.

- Identifying factors that affect medical emergency demand requiring the dispatch of an ambulance (Paper VI).

Including this information can be useful for the proactive planning of preventive actions by emergency managers and policymakers. 


\section{Conclusions and future research}

This chapter presents the conclusions of the thesis and based on the conducted research, proposes directions for further research.

\subsection{Conclusions}

In this thesis, research was conducted focusing on developing models, methods, and strategies for the use of volunteers in daily medical emergency response. For this purpose, OR was used and the results were presented in the form of six papers. These results show the potential of OR-based models and methods in facilitating the task assignment and dispatch of volunteers for daily medical emergency response as well as in providing information about factors affecting the creation of medical emergency demand. The conducted studies show that OR can provide solutions to problems that do not always have trivial answers. These solutions and information can contribute to better decision-making. Access to more information about future demand for EMS, to some of which volunteers can be sent, and the factors affecting this demand, can help medical emergency managers to plan their operational and tactical activities. In the context of daily medical emergency management, making better decisions means the possibility of saving more lives and reducing human suffering.

Even though much research has already investigated daily emergency management and the emergency response process using OR, including the models and method developed in this thesis, there remain areas for further research in which OR can play a positive part.

\subsection{Future research}

To further improve daily medical emergency response, especially using OR, future research is needed in several areas.

First, considering the utilization of volunteers for different medical emergencies. In this thesis, models and methods were developed primarily for the dispatch of volunteers to OHCA cases. As shown in the review paper in this thesis (Paper I), unlike other novel (human) resources, most studies on volunteers have focused on the use of this resource for OHCA. However, the employment of volunteers in other 
types of medical emergency responses, such as bleeding or trauma, and the potential gained benefits from their utilization could be investigated and then modeled using OR.

Second, utilizing several novel resources in a medical emergency response. In this thesis, the employment of volunteers in response to OHCA as well as the use of mobile AEDs, in the form of privately-owned vehicles equipped with AEDs or volunteers who can carry AEDs with them, were studied and modeled. The developed models and methods can be extended in two ways. First, other means of delivery of AEDs to the scene of an OHCA, such as drones, public transportation (e.g., buses), and taxis, along with the uncertainties associated with them, can be incorporated into the models. Second, other types of novel human resources, such as CFR and first responders, can also be included in the models.

Third, considering differences between volunteers when making a task assignment and dispatch decision. The models and methods developed in this thesis have assumed that all volunteers have similar capabilities and behaviors. One improvement to these models is the consideration of differences between volunteers. Different capabilities and behaviors can lead to different dispatch and task assignment decisions, which can potentially result in different outcomes. The performance of volunteers who have responded to prior emergencies, such as OHCA cases, can be measured. These volunteers can be ranked based on their previous performances, as well as their capability measures, and future decisions about task assignment and dispatch can be made based on these measures.

Fourth, developing more general models for the utilization of novel resources. While the use of novel resources (e.g., volunteers) for different daily medical emergency responses, as well as other daily emergency responses, is one extension of this work, another extension is to consider the use of these resources for emergencies of different magnitudes. Thus, developing models for the use of these resources across the emergency spectrum, ranging from daily emergencies to disasters, is another direction for future research.

Fifth, improving the model for the forecast of medical emergency calls with the use of real-time data and making a real-time forecast of the number of medical emergency calls. This real-time data could include people's mobility, weather data, and traffic data. People's mobility can be obtained by means of mobile phone tracking data to estimate the number of people in a geographical zone. This mobility data could compensate for the shortcomings of the currently existing population data. These shortcomings occur because the existing population data is already at least one year old when it is made available, and it does not capture where people 
actually are in each zone, that is, it is static. This old, static data is thus incapable of capturing temporary population density changes in zones.

Sixth, extending the forecasting model so that it can make predictions about a wider range of emergencies. The model developed in this thesis is designed to forecast the number of emergency calls to which medical services respond. A more generalized model would have the capability of forecasting calls both for medical emergencies and those requiring fire and rescue services. 
Models for Dispatch of Volunteers in Daily Emergency Response 


\section{References}

Akademiska Sjukhuset. (n.d.-a). Alarm central [Larmcentral]. Retrieved March 2, 2021, from https://www.akademiska.se/forvardgivare/verksamhetsomraden/ambulanssjukvard/larmcentral/

Akademiska Sjukhuset. (n.d.-b). In the wait of an ambulance [I väntan på ambulans (IVPA)]. Retrieved June 28, 2020, from https://www.akademiska.se/forvardgivare/verksamhetsomraden/ambulanssjukvard/i-vantan-pa-ambulansivpa/

Aldrich, C. A., Hisserich, J. C., and Lave, L. B. (1971). An analysis of the demand for emergency ambulance service in an urban area. American Journal of Public Health, 61(6), 1156-1169.

Altiok, T., and Melamed, B. (2007). Simulation modeling and analysis with Arena. Academic

Press.

https://login.e.bibl.liu.se/login?url=https://search.ebscohost.com/login.aspx?di rect=true \&AuthType $=\mathrm{ip}, \mathrm{uid} \& \mathrm{db}=\mathrm{cat} 00115 \mathrm{a} \& \mathrm{AN}=\mathrm{kpp} .654877 \&$ lang $=\mathrm{sv} \&$ site $=$ eds-live \&scope $=$ site

Ambulancezorg Nederland (AZN). (n.d.). Ambulancezorg Nederland (AZN). Retrieved July 16, 2021, from https://www.ambulancezorg.nl/en/azn/ambulancezorg-nederland-association

Andelius, L., Oving, I., Folke, F., de Graaf, C., Stieglis, R., Kjoelbye, J. S., Hansen, C. M., Koster, R. W., L Tan, H., and Blom, M. T. (2021). Management of first responder programmes for out-of-hospital cardiac arrest during the COVID-19 pandemic in Europe. Resuscitation Plus, 5(November), 100075. https://doi.org/10.1016/j.resplu.2020.100075

Andersson, T., and Värbrand, P. (2007). Decision support tools for ambulance dispatch and relocation. Journal of the Operational Research Society, 58(2), 195-201. https://doi.org/10.1057/palgrave.jors.2602174

Aringhieri, R., Bruni, M. E., Khodaparasti, S., and van Essen, J. T. (2017). Emergency medical services and beyond: Addressing new challenges through a wide literature review. Computers and Operations Research, 78(September 2016), 349-368. https://doi.org/10.1016/j.cor.2016.09.016

Auricchio, A., Gianquintieri, L., Burkart, R., Benvenuti, C., Muschietti, S., Peluso, S., Mira, A., Moccetti, T., and Caputo, M. L. (2019). Real-life time and distance covered by lay first responders alerted by means of smartphone-application: Implications for early initiation of cardiopulmonary resuscitation and access to automatic external defibrillators. Resuscitation, 141(December 2018), 182187. https://doi.org/10.1016/j.resuscitation.2019.05.023 
Backes, A. (2020). Räddningstjänstens förmåga vid IVPA (i väntan på ambulans) En studie om räddningstjänstens förmåga att utföra IVPA-uppdrag [Luleå tekniska universitet]. https://ltu.divaportal.org/smash/get/diva2:1427537/FULLTEXT01.pdf

Bäckman, A., Hollenberg, J., Svensson, L., Ringh, M., Nordberg, P., Djärv, T., Forsberg, S., Hernborg, O., and Claesson, A. (2018). Drones for Provision of Flotation Support in Simulated Drowning. Air Medical Journal, 37(3), 170173.

Balasingam, M. (2017). Drones in medicine-The rise of the machines. International Journal of Clinical Practice, 71(9), e12989.

Bandara, D., Mayorga, M. E., and Mclay, L. A. (2014). Priority dispatching strategies for EMS systems. Journal of the Operational Research Society, 65(4), 572-587. https://doi.org/10.1057/jors.2013.95

Bandara, D., Mayorga, M. E., and McLay, L. A. (2012). Optimal dispatching strategies for emergency vehicles to increase patient survivability. International Journal of Operational Research, 15(2), 195-214. https://doi.org/10.1504/IJOR.2012.048867

Banks, J. (2014). Discrete-event system simulation. (5., Pearso). Prentice Hall. https://login.e.bibl.liu.se/login?url=https://search.ebscohost.com/login.aspx?di rect $=$ true $\& \mathrm{db}=$ cat $00115 \mathrm{a} \& \mathrm{AN}=1 \mathrm{kp} .1027121 \&$ lang $=$ sv\&site=edslive $\&$ scope $=$ site

Barry, T., Guerin, S., and Bury, G. (2019). Motivation, challenges and realities of volunteer community cardiac arrest response: a qualitative study of 'lay'community first responders. BMJ Open, 9(8), e029015.

Bélanger, V., Lanzarone, E., Nicoletta, V., Ruiz, A., and Soriano, P. (2020). A recursive simulation-optimization framework for the ambulance location and dispatching problem. European Journal of Operational Research, 286(2), 713725. https://doi.org/10.1016/j.ejor.2020.03.041

Bélanger, V., Ruiz, A., and Soriano, P. (2019). Recent optimization models and trends in location, relocation, and dispatching of emergency medical vehicles. European Journal of Operational Research, 272(1), 1-23.

Berglund, E., Claesson, A., Nordberg, P., Djärv, T., Lundgren, P., Folke, F., Forsberg, S., Riva, G., and Ringh, M. (2018). A smartphone application for dispatch of lay responders to out-of-hospital cardiac arrests. Resuscitation, 126, $160-165$.

Berkoune, D., Renaud, J., Rekik, M., and Ruiz, A. (2012). Transportation in disaster response operations. Socio-Economic Planning Sciences, 46(1), 23-32. https://doi.org/10.1016/j.seps.2011.05.002

Berlin, J. M., and Carlström, E. D. (2011). Why is collaboration minimised at the accident scene? Disaster Prevention and Management: An International Journal, 20(2), 159-171. https://doi.org/10.1108/09653561111126094 
Bertsimas, D., and Ng, Y. (2019). Robust and stochastic formulations for ambulance deployment and dispatch. European Journal of Operational Research, 279(2), 557-571. https://doi.org/10.1016/j.ejor.2019.05.011

Boland, L. L., Satterlee, P. A., Fernstrom, K. M., Hanson, K. G., Desikan, P., and LaCroix, B. K. (2015). Advanced clinical interventions performed by emergency medical responder firefighters prior to ambulance arrival. Prehospital Emergency Care, 19(1), 96-102. https://doi.org/10.3109/10903127.2014.942477

Bonnet, B., Gama Dessavre, D., Kraus, K., and Ramirez-Marquez, J. E. (2015). Optimal placement of public-access AEDs in urban environments. Computers and Industrial Engineering, 90, 269-280. https://doi.org/10.1016/j.cie.2015.09.012

Bos, N., Krol, M., Veenvliet, C., and Plass, A. M. (2015). Ambulance care in Europe: organization and practices of ambulance services in 14 European countries. http://www.nivel.nl

Boujemaa, R., Jebali, A., Hammami, S., and Ruiz, A. (2020). Multi-period stochastic programming models for two-tiered emergency medical service system. Computers and Operations Research, 123, 104974. https://doi.org/10.1016/j.cor.2020.104974

Brandskyddsföreningen Södermanland. (n.d.). Civil insatsperson (CIP). Retrieved February 12, 2021, from https://www.brandskyddsforeningen.se/regionalaforeningar/brandskyddsforeningen-sodermanland/om-oss/information-omcivil-insatsperson-cip/

Bull-Kamanga, L., Diagne, K., Lavell, A., Leon, E., Lerise, F., MacGregor, H., Maskrey, A., Meshack, M., Pelling, M., Reid, H., Satterthwaite, D., Songsore, J., Westgate, K., and Yitambe, A. (2003). From everyday hazards to disasters: the accumulation of risk in urban areas. Environment and Urbanization, 15(1), 193-204. https://doi.org/10.1177/095624780301500109

Cairns, K. J., Marshall, A. H., and Kee, F. (2011). Using simulation to assess cardiac first-responder schemes exhibiting stochastic and spatial complexities. Journal of the Operational Research Society, 62(6), 982-991. https://doi.org/10.1057/jors.2010.27

Campbell, A., and Ellington, M. (2016). Reducing time to first on scene: an ambulance-community first responder scheme. Emergency Medicine International, 2016.

Capucci, A., Aschieri, D., Guerra, F., Pelizzoni, V., Nani, S., Villani, G. Q., and Bardy, G. H. (2016). Community-based automated external defibrillator only resuscitation for out-of-hospital cardiac arrest patients. American Heart Journal, 172, 192-200. https://doi.org/10.1016/j.ahj.2015.10.018

Caputo, M. L., Muschietti, S., Burkart, R., Benvenuti, C., Conte, G., Regoli, F., Mauri, R., Klersy, C., Moccetti, T., and Auricchio, A. (2017). Lay persons alerted by mobile application system initiate earlier cardio-pulmonary 
resuscitation: A comparison with SMS-based system notification. Resuscitation, 114, 73-78. https://doi.org/10.1016/j.resuscitation.2017.03.003

Carvalho, A. S., Captivo, M. E., and Marques, I. (2020). Integrating the ambulance dispatching and relocation problems to maximize system's preparedness. European Journal of Operational Research, 283(3), 1064-1080. https://doi.org/10.1016/j.ejor.2019.11.056

Chan, T. C. Y., Demirtas, D., and Kwon, R. H. (2016). Optimizing the deployment of public access defibrillators. Management Science, 62(12), 3617-3635. https://doi.org/10.1287/mnsc.2015.2312

Chan, T. C. Y., Li, H., Lebovic, G., Tang, S. K., Chan, J. Y. T., Cheng, H. C. K., Morrison, L. J., and Brooks, S. C. (2013). Identifying Locations for Public Access Defibrillators Using Mathematical Optimization. Circulation, 127(17), 1801-1809.

Chan, T. C. Y., Shen, Z.-J. M., and Siddiq, A. (2018a). Robust defibrillator deployment under cardiac arrest location uncertainty via row-and-column generation. Operations Research, 66(2), 358-379.

Chan, T. C. Y., Shen, Z. J. M., and Siddiq, A. (2018b). Robust defibrillator deployment under cardiac arrest location uncertainty via row-and-column generation. Operations Research, 66(2), 358-379. https://doi.org/10.1287/opre.2017.1660

Channouf, N., L'Ecuyer, P., Ingolfsson, A., and Avramidis, A. N. (2007). The application of forecasting techniques to modeling emergency medical system calls in Calgary, Alberta. Health Care Management Science, 10(1), 25-45. https://doi.org/10.1007/s10729-006-9006-3

Chanta, S., Mayorga, M. E., and McLay, L. A. (2014). Improving emergency service in rural areas: a bi-objective covering location model for EMS systems. Annals of Operations Research, 221(1), 133-159. https://doi.org/10.1007/s10479-0110972-6

Chen, D.-S., Batson, R. G., and Dang, Y. (2011). Applied integer programming: modeling and solution. John Wiley \& Sons.

Choudhury, E. (2010). Attracting and managing volunteers in local government. Journal of Management Development, 29(6), 592-603. https://doi.org/10.1108/02621711011046558

Chowdhury, S., Emelogu, A., Marufuzzaman, M., Nurre, S. G., and Bian, L. (2017). Drones for disaster response and relief operations: A continuous approximation model. International Journal of Production Economics, 188(March), 167-184. https://doi.org/10.1016/j.ijpe.2017.03.024

Claesson, A., Fredman, D., Svensson, L., Ringh, M., Hollenberg, J., Nordberg, P., Rosenqvist, M., Djarv, T., Österberg, S., Lennartsson, J., and others. (2016). Unmanned aerial vehicles (drones) in out-of-hospital-cardiac-arrest. Scandinavian Journal of Trauma, Resuscitation and Emergency Medicine, 24(1), 124. 
Claesson, A., Svensson, L., Nordberg, P., Ringh, M., Rosenqvist, M., Djarv, T., Samuelsson, J., Hernborg, O., Dahlbom, P., Jansson, A., and Hollenberg, J. (2017). Drones may be used to save lives in out of hospital cardiac arrest due to drowning. Resuscitation, 114, 152-156. https://doi.org/10.1016/j.resuscitation.2017.01.003

Coppola, D. P. (2006). Introduction to international disaster management. Elsevier.

Cowlishaw, S., Evans, L., and McLennan, J. (2008). Families of rural volunteer firefighters. $\quad$ Rural Society, $18(1), \quad 17-25$. https://doi.org/10.5172/rsj.351.18.1.17

Cummins, R., Ornato, J. P., Thies, W. H., Pepe, P. E., Billi, J. E., Seidel, J., Jaffe, A. S., Flint, L. S., Goldstein, S., Abramson, N. S., Brown, C., Chandra, N. C., Gonzalez, E. R., Newell, L., Stults, K. R., and Membrino, G. E. (1991). AIL4 Medical / Scientific Statement Improving Survival From Sudden Cardiac Arrest: The " Chain of Survival " Concept of SURVIVAL. Circulation, 83, 1832-1847. https://doi.org/10.1161/01.CIR.83.5.1832

De Maio, V. J., Stiell, I. G., Wells, G. A., and Spaite, D. W. (2003). Optimal defibrillation response intervals for maximum out-of-hospital cardiac arrest survival rates. Annals of Emergency Medicine, 42(2), 242-250. https://doi.org/10.1067/mem.2003.266

Deakin, C. D., Shewry, E., and Gray, H. H. (2014). Public access defibrillation remains out of reach for most victims of out-of-hospital sudden cardiac arrest. Heart, 100(8), 619-623. https://doi.org/10.1136/heartjnl-2013-305030

Earl, C. P., Parker, E. A., and Capra, M. F. (2005). Volunteers in public health and emergency management at outdoor music festivals ( Part 2 ): a European study. Australian Journal of Emergency Management, 20(1), 31-37.

Earl, C., Stoneham, M., and Capra, M. (2003). Volunteers in Emergency Management at Outdoor Music Festivals. The Australian Journal of Emergency Management, 18(4), 18-24.

Eiselt, H. A., and Sandblom, C.-L. (2012). Operations research: A model-based approach. Springer Science \& Business Media.

Enayati, S., Mayorga, M. E., Toro-Díaz, H., and Albert, L. A. (2019). Identifying trade-offs in equity and efficiency for simultaneously optimizing location and multipriority dispatch of ambulances. International Transactions in Operational Research, 26(2), 415-438. https://doi.org/10.1111/itor.12590

Erickson, P. A. (2006). Emergency Response Planning for Corporate and Municipal Managers. Elsevier.

Erkut, E., Ingolfsson, A., and Erdogan, G. (2008). Ambulance Location for Maximum Survival. Naval Research Logistics, 55(1), 42-58. https://doi.org/10.1002/nav

Falasca, M., and Zobel, C. (2012). An optimization model for volunteer assignments in humanitarian organizations. Socio-Economic Planning Sciences, 46(4), 250 
260. https://doi.org/10.1016/j.seps.2012.07.003

Granberg, T. A., Danielsson, N., Fredriksson, A., Nordström, J., Pilemalm, S., Tjernstrom, R., and Mojir, K. Y. (2016). Using Semi-professionals in Emergency Response. The 16th International Conference on Information Systems for Crisis Response And Management (ISCRAM 2016), May 2016.

Granberg, T. A., Fredriksson, A., Pilemalm, S., and Yousefi Mojir, K. (2017). Effektivt sambruk av kommunala resurser för ökad säkerhet och trygghet.

Groh, W. J., Birnbaum, A., Barry, A., Anton, A., Mann, N. C., Peberdy, M. A., Vijayaraghavan, K., Powell, J., and Mosesso, V. N. (2007). Characteristics of volunteers responding to emergencies in the Public Access Defibrillation Trial. Resuscitation, $72(2)$ 193-199. https://doi.org/10.1016/j.resuscitation.2006.06.036

Gupta, S., Starr, M. K., Farahani, R. Z., and Matinrad, N. (2016). Disaster Management from a POM Perspective: Mapping a New Domain. Production and Operations Management, O(0), 1-27. https://doi.org/10.1111/poms.12591

Habib, M. A., Olajide, B., Terashima, M., and Campbell, S. (2018). Relationship between Neighborhood Characteristics and Demand for Emergency Health Service Vehicles: A Poisson Hurdle Regression Modeling Approach. Transportation Research Record, 2672(3), 80-91. https://doi.org/10.1177/0361198118797459

Haddow, G., Bullock, J., and Coppola, D. P. (2013). Introduction to emergency management. Elsevier.

Haghani, A., and Afshar, A. (2009). Supply chain management in disaster response. September, 1-89. http://trid.trb.org/view.aspx?id=906596

Hallström, V., Ramsell, E., and Yousefi Mojir, K. (2016). Organiserade räddningsinsatser med frivilliga Presentation av några verksamheter som.

Hansen, S. M., Brøndum, S., Thomas, G., Rasmussen, S. R., Kvist, B., Christensen, A., Lyng, C., Lindberg, J., Lauritsen, T. L. B., Lippert, F. K., Torp-Pedersen, C., and Hansen, P. A. (2015). Home care providers to the rescue: A novel firstresponder programme. PLoS ONE, 10(10), 1-10. https://doi.org/10.1371/journal.pone.0141352

Hanssen, Ø. (2015). Rescue Operations Position Tracking in Voluntary Search and Rescue Operations. Proceedings of the ISCRAM 2015 Conference, MAY, 7686.

Hasselqvist-Ax, I., Nordberg, P., Herlitz, J., Svensson, L., Jonsson, M., Lindqvist, J., Ringh, M., Claesson, A., Björklund, J., Andersson, J.-O., and others. (2017). Dispatch of firefighters and police officers in out-of-hospital cardiac arrest: a nationwide prospective cohort trial using propensity score analysis. Journal of the American Heart Association, 6(10), e005873.

Heartrunner Sweden AB. (n.d.). Sms-livräddare. Retrieved February 12, 2021, from https://www.smslivraddare.se/ 
Hillier, F. S. (2010). Introduction to Operations Research. McGraw-Hill.

Hollenberg, J., Riva, G., Bohm, K., Nordberg, P., Larsen, R., Herlitz, J., Pettersson, H., Rosenqvist, M., and Svensson, L. (2009). Dual dispatch early defibrillation in out-of-hospital cardiac arrest: the SALSA-pilot. European Heart Journal, 30(14), 1781-1789.

Høyer, C. B., and Christensen, E. F. (2009). Fire fighters as basic life support responders: a study of successful implementation. Scandinavian Journal of Trauma, Resuscitation and Emergency Medicine, 17, 16. https://doi.org/10.1186/1757-7241-17-16

Hyndman, R. J., and Koehler, A. B. (2006). Another look at measures of forecast accuracy. International Journal of Forecasting, 22(4), 679-688. https://doi.org/10.1016/j.ijforecast.2006.03.001

Iannoni, A. P., Chiyoshi, F., and Morabito, R. (2015). A spatially distributed queuing model considering dispatching policies with server reservation. Transportation Research Part E: Logistics and Transportation Review, 75, 4966. https://doi.org/10.1016/j.tre.2014.12.012

Iannoni, A. P., Morabito, R., and Saydam, C. (2008). A hypercube queueing model embedded into a genetic algorithm for ambulance deployment on highways. Annals of Operations Research, 157(1), 207-224. https://doi.org/10.1007/s10479-007-0195-z

Ingolfsson, A. (2013). EMS planning and management. In G. S. Zaric (Ed.), Operations Research and Health Care Policy (pp. 105-128). Springer, New York. https://doi.org/10.1007/978-1-4614-6507-2_6

Jagtenberg, C. J., and Mason, A. J. (2020). Improving fairness in ambulance planning by time sharing. European Journal of Operational Research, 280(3), 1095-1107. https://doi.org/10.1016/j.ejor.2019.08.003

Jagtenberg, C. J., van den Berg, P. L., and van der Mei, R. D. (2017). Benchmarking online dispatch algorithms for Emergency Medical Services. European Journal of Operational Research, 258(2), 715-725. https://doi.org/10.1016/j.ejor.2016.08.061

Jaldell, H. (2004). Tidsfaktorns betydelse vid räddningsinsatser.

Jonsson, M., Berglund, E., Djärv, T., Nordberg, P., Claesson, A., Forsberg, S., Nord, A., Tan, H. L., and Ringh, M. (2020). A brisk walk-Real-life travelling speed of lay responders in out-of-hospital cardiac arrest. Resuscitation, 151, 197-204. https://doi.org/10.1016/j.resuscitation.2020.01.043

Kamenetzky, R. D., Shuman, L. J., and Wolfe, H. (1982). Estimating need and demand for prehospital care. Operations Research, 30(6), 1148-1167. https://doi.org/10.1287/opre.30.6.1148

Kim, D., Lee, K., and Moon, I. (2019). Stochastic facility location model for drones considering uncertain flight distance. Annals of Operations Research, 283(12), 1283-1302. https://doi.org/10.1007/s 10479-018-3114-6 
Knight, V. A., Harper, P. R., and Smith, L. (2012). Ambulance allocation for maximal survival with heterogeneous outcome measures. Omega, 40(6), 918926. https://doi.org/10.1016/j.omega.2012.02.003

Kooij, F. O., van Alem, A. P., Koster, R. W., and de Vos, R. (2004). Training of police officers as first responders with an automated external defibrillator. Resuscitation, 63(1), 33-41.

Krüger, A. J., Lockey, D., Kurola, J., Di Bartolomeo, S., Castrén, M., Mikkelsen, S., and Lossius, H. M. (2011). A consensus-based template for documenting and reporting in physician-staffed pre-hospital services. Scandinavian Journal of Trauma, Resuscitation and Emergency Medicine, 19(1), 71.

Krüger, A. J., Skogvoll, E., Castrén, M., Kurola, J., and Lossius, H. M. (2010). Scandinavian pre-hospital physician-manned Emergency Medical ServicesSame concept across borders? Resuscitation, 81(4), 427-433. https://doi.org/10.1016/j.resuscitation.2009.12.019

Kvet, M., and Janáček, J. (2018). Fair emergency system design under uncertainty. Central European Journal of Operations Research, 26(3), 599-609. https://doi.org/10.1007/s10100-017-0507-6

Lam, S. S. W., Ng, Y. S., Lakshmanan, M. R., Ng, Y. Y., and Ong, M. E. H. (2016). Ambulance Deployment under Demand Uncertainty. Journal of Advanced Management Science, 4(3), 187-194. https://doi.org/10.12720/joams.4.3.187194

Langhelle, A., Lossius, H. M., Silfvast, T., Björnsson, H. M., Lippert, F. K., Ersson, A., and Søreide, E. (2004). International EMS systems: the Nordic countries. Resuscitation, 61(1), 9-21.

Larsen, M. P., Eisenberg, M. S., Cummins, R. O., and Hallstrom, A. P. (1993). Predicting survival from out-of-hospital cardiac arrest: a graphic model. Annals of Emergency Medicine, 22(11), 1652-1658.

Larson, R. (2005). Decision Models for Emergency Response Planning. In Handbook of Homeland Security.

Lassiter, K., Khademi, A., and Taaffe, K. M. (2015). A robust optimization approach to volunteer management in humanitarian crises. International Journal of Production Economics, 163, 97-111. https://doi.org/10.1016/j.ijpe.2015.02.018

Latuska, K. M., Graf, R. L., Zwislewski, A., Meyer, L. K., Nanassy, A. D., and others. (2019). Stop the bleed training improves knowledge, skills, and confidence among school nurses. The Journal of Continuing Education in Nursing, 50(11), 501-507.

Law, A. M. (2015). Simulation Modeling and Analysis. In McGraw-Hill, Inc. https://doi.org/10.2307/2288169

Lee, C. T., Lee, Y. C., and Chen, A. Y. (2019). In-building automated external defibrillator location planning and assessment through building information 
models. Automation in Construction, 106(June), 102883. https://doi.org/10.1016/j.autcon.2019.102883

Lindström, V., Bohm, K., and Kurland, L. (2015). Präklinische Versorgung in Schweden: Von einer Transportorganisation $\mathrm{zu}$ hochentwickelter medizinischer Versorgung. Notfall Und Rettungsmedizin, 18(2), 107-109. https://doi.org/10.1007/s10049-015-1989-1

Lowthian, J. A., Jolley, D. J., Curtis, A. J., Currell, A., Cameron, P. A., Stoelwinder, J. U., and McNeil, J. J. (2011). The challenges of population ageing: Accelerating demand for emergency ambulance services by older patients, 1995-2015. Medical Journal of Australia, 194(11), 574-578.

Matteson, D. S., McLean, M. W., Woodard, D. B., and Henderson, S. G. (2011). Forecasting emergency medical service call arrival rates. Annals of Applied Statistics, 5(2 B), 1379-1406. https://doi.org/10.1214/10-AOAS442

McCormack, R., and Coates, G. (2015). A simulation model to enable the optimization of ambulance fleet allocation and base station location for increased patient survival. European Journal of Operational Research, 247(1), 294-309. https://doi.org/10.1016/j.ejor.2015.05.040

McLay, L. A., and Mayorga, M. E. (2013a). A dispatching model for server-tocustomer systems that balances efficiency and equity. Manufacturing and Service Operations Management, 15(2), 205-220. https://doi.org/10.1287/msom.1120.0411

McLay, L. A., and Mayorga, M. E. (2013b). A model for optimally dispatching ambulances to emergency calls with classification errors in patient priorities. IIE Transactions (Institute of Industrial Engineers), 45(1), 1-24. https://doi.org/10.1080/0740817X.2012.665200

Mehdiyev, N., Enke, D., Fettke, P., and Loos, P. (2016). Evaluating Forecasting Methods by Considering Different Accuracy Measures. Procedia Computer Science, 95, 264-271. https://doi.org/10.1016/j.procs.2016.09.332

Merriam-Webster. (n.d.). Merriam-Webster dictionary. Retrieved June 24, 2020, from https://www.merriam-webster.com/dictionary/layman

Metelmann, C., Metelmann, B., Kohnen, D., Brinkrolf, P., Andelius, L., Böttiger, B. W., Burkart, R., Hahnenkamp, K., Krammel, M., Marks, T., Müller, M. P., Prasse, S., Stieglis, R., Strickmann, B., and Thies, K. C. (2021). Smartphonebased dispatch of community first responders to out-of-hospital cardiac arrest statements from an international consensus conference. Scandinavian Journal of Trauma, Resuscitation and Emergency Medicine, 29(1), 1-9. https://doi.org/10.1186/s13049-021-00841-1

Missing People Sweden. (n.d.). Missing People Sweden. Retrieved February 12, 2021, from https://www.missingpeople.se/sv/om-oss/

MSB. (n.d.). Myndigheten för samhällsskydd och beredskap. Retrieved March 2, 2021, from https://www.msb.se/ 
Myrick, J. A., Kay, B. J., Kishbaugh, D., Pittman, J. V, and Sayford, N. F. (1983). Acceptance of a volunteer first-responder system in rural communities: A field experiment. Medical Care, 21(4), 389-399.

Naths, G., Jürgens, C., and Peter, A. (2007). First responder als ergänzung des rettungsdienstes: Leistungsvermögen ehrenamtlicher ersthelfersysteme. Notfall Und Rettungsmedizin, 10(5), 350-356. https://doi.org/10.1007/s10049-0070929-0

Nehme, Z., Andrew, E., Bernard, S., Haskins, B., and Smith, K. (2019). Trends in survival from out-of-hospital cardiac arrests defibrillated by paramedics, first responders and bystanders. Resuscitation, 143, 85-91.

NEOS Server. (n.d.). NEOS Server for MINLP/AMPL. Retrieved September 7, 2021, from https://neos-server.org/neos/solvers/minco:MINLP/AMPL.html

Nicoletta, V., Lanzarone, E., Guglielmi, A., Bélanger, V., and Ruiz, A. (2016). A Bayesian Model for Describing and Predicting the Stochastic Demand of Emergency Calls. International Conference on Bayesian Statistics in Action, 203-212.

Nikbakhsh, E., and Farahani, R. Z. (2011). Humanitarian logistics planning in disaster relief operations. Logistics Operations and Management: Concepts and Models, 291. https://doi.org/10.1016/B978-0-12-385202-1.00015-3

Nord, A. (2017). Bystander CPR New aspects of CPR training among students and the importance of bystander education level on survival. Linköping University.

Nordberg, P., Hollenberg, J., Rosenqvist, M., Herlitz, J., Jonsson, M., JärnbertPetterson, H., Forsberg, S., Dahlqvist, T., Ringh, M., and Svensson, L. (2014). The implementation of a dual dispatch system in out-of-hospital cardiac arrest is associated with improved short and long term survival. European Heart Journal: Acute Cardiovascular Care, 3(4), 293-303.

Nordberg, P., Jonsson, M., Forsberg, S., Ringh, M., Fredman, D., Riva, G., Hasselqvist-Ax, I., and Hollenberg, J. (2015). The survival benefit of dual dispatch of EMS and fire-fighters in out-of-hospital cardiac arrest may differ depending on population density--a prospective cohort study. Resuscitation, 90, 143-149.

Oruc, B. E., and Kara, B. Y. (2018). Post-disaster assessment routing problem. Transportation Research Part B: Methodological, 116, 76-102. https://doi.org/10.1016/j.trb.2018.08.002

Oving, I., Masterson, S., Tjelmeland, I. B. M., Jonsson, M., Semeraro, F., Ringh, M., Truhlar, A., Cimpoesu, D., Folke, F., Beesems, S. G., and others. (2019). First-response treatment after out-of-hospital cardiac arrest: a survey of current practices across 29 countries in Europe. Scandinavian Journal of Trauma, Resuscitation and Emergency Medicine, 27(1), 112.

Phung, V. H., Trueman, I., Togher, F., Orner, R., and Siriwardena, A. N. (2017). Community first responders and responder schemes in the United Kingdom: Systematic scoping review. Scandinavian Journal of Trauma, Resuscitation 
and Emergency Medicine, 25(1), 1-9. https://doi.org/10.1186/s13049-0170403-Z

Pijls, R. W. M., Nelemans, P. J., Rahel, B. M., and Gorgels, A. P. M. (2016). A text message alert system for trained volunteers improves out-of-hospital cardiac arrest survival. Resuscitation, $105, \quad 182-187$. https://doi.org/10.1016/j.resuscitation.2016.06.006

Pijls, R. W. M., Nelemans, P. J., Rahel, B. M., and Gorgels, A. P. M. (2019). Characteristics of a novel citizen rescue system for out-of-hospital cardiac arrest in the Dutch province of Limburg: relation to incidence and survival. Netherlands Heart Journal, 27(2), 100-107.

Pilemalm, S., Stenberg, R., and Granberg, T. A. (2013). Emergency Response in Rural Areas. International Journal of Information Systems for Crisis Response and Management, 5(2), 19-31. https://doi.org/10.4018/jiscrm.2013040102

Pozner, C. N., Zane, R., Nelson, S. J., and Levine, M. (2004). International EMS Systems: The United States: Past, present, and future. Resuscitation, 60(3), 239-244. https://doi.org/10.1016/j.resuscitation.2003.11.004

Pulver, A., and Wei, R. (2018). Optimizing the spatial location of medical drones. Applied Geography, 90(July 2016), 9-16. https://doi.org/10.1016/j.apgeog.2017.11.009

Quarantelli, E. L. (1995). Disasters Are Different, Therefore Planning For And Managing Them Requires Innovative As Well As Traditional Behaviors. Disasters.

Quarantelli, E. L. (2000). Emergencies, Disaster and Catastrophes are different phenomena. Disaster Research Center, 682-688. http://udspace.udel.edu/handle/19716/674

Ramsell, E., Pilemalm, S., and Granberg, T. A. (2017). Using Volunteers for Emergency Response in Rural Areas - Network Collaboration Factors and IT support in the Case of Enhanced Neighbors. 14th International Conference on Information Systems for Crisis Response and Management (ISCRAM 2017), 985-995.

Ramsell, E., Pilemalm, S., and Granberg, T. A. (2019). Identifying functions for smartphone based applications in volunteer emergency response. Proceedings of the International ISCRAM Conference, 2019-May(May), 1044-1056.

Ringh, M., Fredman, D., Nordberg, P., Stark, T., and Hollenberg, J. (2011). Mobile phone technology identifies and recruits trained citizens to perform CPR on outof-hospital cardiac arrest victims prior to ambulance arrival. Resuscitation, 82(12), 1514-1518. https://doi.org/10.1016/j.resuscitation.2011.07.033

Ringh, M., Rosenqvist, M., Hollenberg, J., Jonsson, M., Fredman, D., Nordberg, P., Järnbert-Pettersson, H., Hasselqvist-Ax, I., Riva, G., and Svensson, L. (2015). Mobile-Phone Dispatch of Laypersons for CPR in Out-of-Hospital Cardiac Arrest. New England Journal of Medicine, 372(24), 2316-2325. https://doi.org/10.1056/NEJMoa1406038 
Robinson, S. (2014). Simulation : The Practice of Model Development and Use: Vol. 2nd editio. Palgrave Macmillan. https://login.e.bibl.liu.se/login?url=https://search.ebscohost.com/login.aspx?di rect=true \&AuthType=ip,uid $\& \mathrm{db}=$ nlebk $\& A N=1524148 \&$ lang=sv \&site=edslive $\&$ scope $=$ site

Rottkemper, B., Fischer, K., Blecken, A., and Danne, C. (2011). Inventory relocation for overlapping disaster settings in humanitarian operations. $O R$ Spectrum, 33(3), 721-749. https://doi.org/10.1007/s00291-011-0260-5

Royston, G. (2013). Operational Research for the real world: Big questions from a small island. Journal of the Operational Research Society, 64(6), 793-804. https://doi.org/10.1057/jors.2012.188

Sanders, N. (2015). Forecasting Fundamentals. Business Expert Press. http://ebookcentral.proquest.com/lib/linkoping-

ebooks/detail.action?docID $=4742536$

Saner, H., Morger, C., Eser, P., and von Planta, M. (2013). Dual dispatch early defibrillation in out-of-hospital cardiac arrest in a mixed urban-rural population. Resuscitation, 84(9), 1197-1202. https://doi.org/10.1016/j.resuscitation.2013.02.023

Sanfridsson, J., Sparrevik, J., Hollenberg, J., Nordberg, P., Djärv, T., Ringh, M., Svensson, L., Forsberg, S., Nord, A., Andersson-Hagiwara, M., and Claesson, A. (2019). Drone delivery of an automated external defibrillator - A mixed method simulation study of bystander experience. Scandinavian Journal of Trauma, Resuscitation and Emergency Medicine, 27(1), 1-9. https://doi.org/10.1186/s13049-019-0622-6

Schierbeck, S., Hollenberg, J., Nord, A., Svensson, L., Nordberg, P., Ringh, M., Forsberg, S., Lundgren, P., Axelsson, C., and Claesson, A. (2021). Automated external defibrillators delivered by drones to patients with suspected out-ofhospital cardiac arrest. European Heart Journal, 1-10. https://doi.org/10.1093/eurheartj/ehab498

Schmid, V. (2012). Solving the dynamic ambulance relocation and dispatching problem using approximate dynamic programming. European Journal of Operational Research, 219(3), 611-621. https://doi.org/10.1016/j.ejor.2011.10.043

Scholten, A. C., van Manen, J. G., van der Worp, W. E., IJzerman, M. J., and Doggen, C. J. M. (2011). Early cardiopulmonary resuscitation and use of Automated External Defibrillators by laypersons in out-of-hospital cardiac arrest using an SMS alert service. Resuscitation, 82(10), 1273-1278. https://doi.org/10.1016/j.resuscitation.2011.05.008

Scquizzato, T., Pallanch, O., Belletti, A., Frontera, A., Cabrini, L., Zangrillo, A., and Landoni, G. (2020). Enhancing citizens response to out-of-hospital cardiac arrest: A systematic review of mobile-phone systems to alert citizens as first responders. Resuscitation, 152(May), 16-25. https://doi.org/10.1016/j.resuscitation.2020.05.006 
Seguin, C., Blaquière, G., Loundou, A., Michelet, P., and Markarian, T. (2018). Unmanned aerial vehicles (drones) to prevent drowning. Resuscitation, 127, 63-67.

Setzler, H., Saydam, C., and Park, S. (2009). EMS call volume predictions: A comparative study. Computers and Operations Research, 36(6), 1843-1851. https://doi.org/10.1016/j.cor.2008.05.010

Slaa, G. (2020). Increasing cardiac arrest survival by improving the volunteer alerting algorithm. University of Twente.

Smith, C. M., Wilson, M. H., Ghorbangholi, A., Hartley-Sharpe, C., Gwinnutt, C., Dicker, B., and Perkins, G. D. (2017). The use of trained volunteers in the response to out-of-hospital cardiac arrest--the GoodSAM experience. Resuscitation, 121, 123-126.

Smith, K., Rich, D., Pinol, J. P., Hankin, J., and McNeil, J. (2001). Acceptance of a medical first-responder role by fire fighters. Resuscitation, 51(1), 33-38. https://doi.org/10.1016/S0300-9572(01)00385-9

Socialstyrelsen. (2009). Hälso-och Sjukvårdsrapport 2009.

Socialstyrelsen. (2016). SOSFS 2000:1. november, 1-9.

Song, B. D., Park, K., and Kim, J. (2018). Persistent UAV delivery logistics: MILP formulation and efficient heuristic. Computers $\backslash \&$ Industrial Engineering, 120, 418-428.

Sören, S., Linda, W., and Veronica, L. (2016). Development of the Pre-hospital Emergency Care, The Registered Nurses' Role in the Ambulance Service- A Swedish Perspective. Emergency Medicine: Open Access, 06(01), 1-4. https://doi.org/10.4172/2165-7548.1000294

SOS Alarm. (n.d.). SOS Alarm. Retrieved March 2, 2021, from https://www.sosalarm.se/

SOS Alarm. (2018). SOS Alarm's annual report [SOS Alarms årsberättelse].

Statistics Netherlands (CBS). (n.d.). The population of the Netherlands. Retrieved July 15, 2021, from https://www.cbs.nl/en-gb/visualisations/dashboardpopulation

Stein, P., Spahn, G. H., Müller, S., Zollinger, A., Baulig, W., Brüesch, M., Seifert, B., and Spahn, D. R. (2017). Impact of city police layperson education and equipment with automatic external defibrillators on patient outcome after out of hospital cardiac arrest. Resuscitation, 118, 27-34. https://doi.org/10.1016/j.resuscitation.2017.06.017

Steins, K., Matinrad, N., and Granberg, T. A. (2019). Forecasting the demand for emergency medical services. Proceedings of the 52nd Hawaii International Conference on System Sciences.

Stenberg, R., Pilemalm, S., and Yousefi Mojir, K. (2014). Samverkansformer för räddning och respons Exempel och förslag [Forms of collaboration for rescue and response Examples and suggestions] (Issue 12). https://liu.se/artikel/carer- 
rapportserie

Stenberg, R., Wolmesjö, M., and Leicht, A. (2019). Efterforskning av försvunna personer: en internationell forskningsöversikt. Linköping University Electronic Press.

Stroop, R., Kerner, T., Strickmann, B., and Hensel, M. (2020). Mobile phone-based alerting of CPR-trained volunteers simultaneously with the ambulance can reduce the resuscitation-free interval and improve outcome after out-of-hospital cardiac arrest: A German, population-based cohort study. Resuscitation, 147(March 2019), 57-64. https://doi.org/10.1016/j.resuscitation.2019.12.012

Sun, J. H., and Wallis, L. A. (2012). The emergency first aid responder system model: Using community members to assist life-threatening emergencies in violent, developing areas of need. Emergency Medicine Journal, 29(8), 673678. https://doi.org/10.1136/emermed-2011-200271

Svenson, J. E. (2000). Patterns of use of emergency medical transport: a populationbased study. The American Journal of Cardiology, 18(2), 130-134. https://doi.org/10.1016/S0735-6757(00)90002-0

Swedish Statistics Central Office (SCB). (n.d.). The population of Sweden [Sveriges befolkning]. Retrieved March 2, 2021, from https://scb.se/hittastatistik/sverige-i-siffror/manniskorna-i-sverige/sveriges-befolkning/

Swersey, A. J. (1994). The deployment of police, fire, and emergency medical units. Handbooks in Operations Research and Management Science, 6(C), 151-200. https://doi.org/10.1016/S0927-0507(05)80087-8

Taber, N. (2008). Emergency response: Elearning for paramedics and firefighters. Simulation and Gaming, 39(4), 515-527. https://doi.org/10.1177/1046878107306669

Tamminen, J. I., Hoppu, S. E., and Kämäräinen, A. J. J. (2019). Professional firefighter and trained volunteer first-responding units in emergency medical service. Acta Anaesthesiologica Scandinavica, 63(1), 111-116. https://doi.org/10.1111/aas.13224

Tatham, P., and Kovács, G. (2010). The application of "swift trust" to humanitarian logistics. International Journal of Production Economics, 126(1), 35-45. https://doi.org/10.1016/j.ijpe.2009.10.006

Timmons, S., and Vernon-Evans, A. (2013). Why do people volunteer for community first responder groups? Emergency Medicine Journal, 30(3), 1-5. https://doi.org/10.1136/emermed-2011-200990

Torlén, K., Kurland, L., Castrén, M., Olanders, K., and Bohm, K. (2017). A comparison of two emergency medical dispatch protocols with respect to accuracy. Scandinavian Journal of Trauma, Resuscitation and Emergency Medicine, 25(1), 1-8.

Toro-Díaz, H., Mayorga, M. E., Chanta, S., and McLay, L. A. (2013). Joint location and dispatching decisions for Emergency Medical Services. Computers and 
Industrial Engineering, 64(4), 917-928. https://doi.org/10.1016/j.cie.2013.01.002

Toro-Díaz, H., Mayorga, M. E., McLay, L. A., Rajagopalan, H. K., and Saydam, C. (2015). Reducing disparities in large-scale emergency medical service systems. Journal of the Operational Research Society, 66(7), 1169-1181. https://doi.org/10.1057/jors.2014.83

Toyokuni, Y., Suzukawa, M., Yamashita, K., Yonekawa, C., Kubota, K., Yasuda, Y., Kobayashi, A., and Matsubara, H. (2013). Introduction of the community first responder system into Japan: is that possible? International Journal of Emergency Medicine, 6(1), 34.

Trudeau, P., Rousseau, J.-M., Ferland, J. A., and Choquette, J. (1989). An Operations Research Approach For The Planning and Operation Of An Ambulance Service. INFOR: Information Systems and Operational Research, 27(1), 95-113. https://doi.org/10.1080/03155986.1989.11732084

Tsai, Y., Chang, K.-W., Yiang, G.-T., and Lin, H.-J. (2018). Demand Forecast and Multi-Objective Ambulance Allocation. International Journal of Pattern Recognition and Artificial Intelligence, 32(07), 1859011. https://doi.org/10.1142/s0218001418590115

Universitetssjukhuset i Linköping, and Katastrofmedicinskt centrum. (2020). IVPARegion Östergötland.

Valenzuela, T. D., Roe, D. J., Cretin, S., Spaite, D. W., and Larsen, M. P. (1997). Estimating effectiveness of cardiac arrest interventions: a logistic regression survival model. Circulation, 96(10), 3308-3313.

Valeriano, A., Van Heer, S., de Champlain, F., and C. Brooks, S. (2021). Crowdsourcing to save lives: A scoping review of bystander alert technologies for out-of-hospital cardiac arrest. Resuscitation, 158(July), 94-121. https://doi.org/10.1016/j.resuscitation.2020.10.035

Waalewijn, R. A., De Vos, R., Tijssen, J. G. P., and Koster, R. W. (2001). Survival models for out-of-hospital cardiopulmonary resuscitation from the perspectives of the bystander, the first responder, and the paramedic. Resuscitation, 51(2), 113-122. https://doi.org/10.1016/S0300-9572(01)00407-5

Weinholt, A. (2015). Exploring Collaboration Between the Fire and Rescue Service and New Actors - Cost-efficiency and Adaptation. Linköping University.

Wheelwright, S., Makridakis, S., and Hyndman, R. J. (1998). Forecasting: methods and applications. John Wiley \& Sons.

Winship, C., Boyle, M., and Williams, B. (2014). Out of Hospital Cardiac Arrest Management by First Responders: Retrospective Review of a Fire Fighter First Responder Program. Australasian Journal of Paramedicine, 11(5). https://doi.org/10.33151/ajp.11.5.59

Wong, H. T., and Lai, P. C. (2012). Weather inference and daily demand for emergency ambulance services. Emergency Medicine Journal, 29(1), 60-64. 
http://emj.bmj.com/content/29/1/60.full.pdf\%5Cnhttp://ovidsp.ovid.com/ovid web.cgi? $\mathrm{T}=\mathrm{JS} \& \mathrm{PAGE}=\mathrm{reference} \& \mathrm{D}=\mathrm{emed} 10 \& \mathrm{NEWS}=\mathrm{N} \& \mathrm{AN}=2011711268$

Wong, H. T., Lin, T. K., and Lin, J. J. (2019). Identifying rural-urban differences in the predictors of emergency ambulance service demand and misuse. Journal of the Formosan Medical Association, 118(1P2), 324-331. https://doi.org/10.1016/j.jfma.2018.05.013

Wulterkens, D. (n.d.). Journal of Emergency Medical Services (JEMS). Retrieved July 15, 2021, from https://www.jems.com/patient-care/ems-netherlandsdutch-treat/\#

Yousefi Mojir, K. (2016). New Forms of Collaboration in Emergency Response Systems: A framework for participatory design of information systems [Linköping University]. In Linköping University Electronic Press. https://doi.org/10.3384/lic.diva-129233

Yousefi Mojir, K., and Pilemalm, S. (2016). Actor-centred emergency response systems: a framework for needs analysis and information systems development. International Journal of Emergency Management, 12(4), 403-434. https://doi.org/10.1504/IJEM.2016.079844

Yousefi Mojir, K., and Pilemalm, S. (2013). A framework for new actors in emergency response systems. The 10th International Conference on Information Systems for Crisis Response and Management (ISCRAM 2013), 741-746.

Yu, L., Yang, H., Miao, L., and Zhang, C. (2019). Rollout algorithms for resource allocation in humanitarian logistics. IISE Transactions, 51(8), 887-909. https://doi.org/10.1080/24725854.2017.1417655

Zijlstra, J. A., Stieglis, R., Riedijk, F., Smeekes, M., van der Worp, W. E., and Koster, R. W. (2014). Local lay rescuers with AEDs, alerted by text messages, contribute to early defibrillation in a Dutch out-of-hospital cardiac arrest dispatch system. Resuscitation, 85(11), 1444-1449. 


\section{Papers}

The papers associated with this thesis have been removed for copyright reasons. For more details about these see:

https://doi.org/10.3384/9789179291853 


\section{FACULTY OF SCIENCE AND ENGINEERING}

Linköping Studies in Science and Technology, Dissertation No. 2203, 2022 Department of Science and Technology

Linköping University

SE-581 83 Linköping, Sweden

www.liu.se 